NBER WORKING PAPER SERIES

\title{
AN INFORMATION-BASED TRADE OFF BETWEEN FOREIGN DIRECT INVESTMENT AND FOREIGN PORTFOLIO INVESTMENT
}

\author{
Itay Goldstein \\ Assaf Razin \\ Working Paper 11757 \\ http://www.nber.org/papers/w11757 \\ NATIONAL BUREAU OF ECONOMIC RESEARCH \\ 1050 Massachusetts Avenue \\ Cambridge, MA 02138 \\ November 2005
}

We thank Patrick Bolton, Charles Engel, Amit Goyal, Alexander Guembel, Michael Klein, Enrique Mendoza, Maury Obstfeld, Jacob Sagi, the late Oved Yosha, two referees, and the editor (Linda Tesar) for valuable discussions and comments. We also thank seminar participants at Cornell University, London Business School, Tel Aviv University, the University of California at Berkeley and participants at the following conferences: The LACEA annual meeting (October 2002), the fall meeting of the NBER IFM research group (October 2002), the Summer Meetings of the Econometric Society (June 2003), the International Finance Conference at Georgia Tech (April 2004), and the WFA annual meeting (June 2005). All remaining errors are ours. The views expressed herein are those of the author(s) and do not necessarily reflect the views of the National Bureau of Economic Research.

(C2005 by Itay Goldstein and Assaf Razin. All rights reserved. Short sections of text, not to exceed two paragraphs, may be quoted without explicit permission provided that full credit, including (C notice, is given to the source. 
An Information-Based Trade Off between Foreign Direct Investment and Foreign Portfolio Investment

Itay Goldstein and Assaf Razin

NBER Working Paper No. 11757

November 2005

JEL No. F3, G3

\begin{abstract}
$\underline{\text { ABSTRACT }}$
The paper develops a model of foreign direct investments (FDI) and foreign portfolio investments (FPI). The model describes an information-based trade off between direct investments and portfolio investments. Direct investors are more informed about the fundamentals of their projects. This information enables them to manage their projects more efficiently. However, it also creates an asymmetric-information problem in case they need to sell their projects prematurely, and reduces the price they can get in that case. As a result, investors, who know they are more likely to get a liquidity shock that forces them to sell early, are more likely to choose portfolio investments, whereas investors, who know they are less likely to get a liquidity shock, are more likely to choose direct investments. FDI is characterized by hands-on management style which enables the owner to obtain relatively refined information about the productivity of the firm. This superiority of FDI relative to FPI, comes with a cost: a firm owned by the relatively well-informed FDI investor has a low resale price because of a "lemons" type asymmetric information between the owner and potential buyers. The model can explain several stylized facts regarding foreign equity flows, such as the larger ratio of FDI to FPI inflows in developing countries relative to developed countries, and the greater volatility of FDI net inflows relative to FPI net inflows.
\end{abstract}

Itay Goldstein

Finance Department

The Wharton School

University of Pennsylvania

3620 Locust Walk

Philadelphia, PA 19104

itayg@wharton.upenn.edu
Assaf Razin

Department of Economics

Cornell University

Ithaca, NY 14583

and NBER

razin@post.tau.ac.il 


\section{Introduction}

International equity flows are the main feature of the recent globalization of capital markets both in developing and in developed economies. These flows take two major forms: Foreign Direct Investments (FDI) and Foreign Portfolio Investments (FPI). An empirical regularity is that the share of FDI in total foreign equity flows is larger for developing countries than for developed countries. ${ }^{1}$ Regarding the second moments of foreign equity flows, it is known that the volatility of FDI net inflows is, in general, much smaller than that of FPI net inflows. ${ }^{2}$ Moreover, empirical analysis has established that the differences in volatility between FPI and FDI flows are much smaller for developed economies than for developing economies. ${ }^{3}$

Despite the empirical interest in foreign equity flows, very little work has been done on jointly explaining FDI and FPI in a rigorous theoretical framework. In this paper, we propose such a framework, and provide a model of a trade off between FDI and FPI, which is consistent with the empirical facts mentioned above.

Our model highlights a key difference between the two types of investment: FDI investors, who take both ownership and control positions in the domestic firms, are in effect the managers of the firms under their control; whereas FPI investors, who gain ownership without control of domestic firms, must delegate decisions to managers, but limit their freedom to make decisions because the managers' agenda may not be always consistent with that of the owners. Consequently, due to an agency problem between managers and owners, portfolio investment projects are managed less efficiently than direct investment projects. ${ }^{4}$ To be more specific, direct investors, who act effectively

\footnotetext{
${ }^{1}$ For a summary, based on World Bank data, see Albuquerque (2003).

${ }^{2}$ Net inflows account for net investments made by foreign investors (that is, new investments by foreign investors minus withdrawals of old investments by foreign investors).

Using World Bank data on 111 countries, Albuquerque (2003) shows that $89 \%$ of the countries in his sample have lower coefficient of variation of net FDI inflows than that of other net inflows. A related set of evidence suggests that FDI has proven to be much more resilient during financial crises, and thus contributes to the stability of the host country. (See: Chuhan, Perez-Quiros and Popper, 1996; Frankel and Rose, 1996; Lipsey, 2001; and Sarno and Taylor, 1999).

${ }^{3}$ Lipsey (1999) shows that the ratio of FDI's volatility to other long-term flows' volatility is 0.59 in Latin America, 0.74 in South East Asia, 0.86 in Europe, and 0.88 in the US. Thus, the differences in volatilities between net FDI inflows and other types of net inflows are smaller in developed economies.

${ }^{4}$ For a recent survey on agency problems and their effect on financial contracting, see: Hart (2001).
} 
as managers of their own projects, are more informed than portfolio investors regarding changes in the prospects of their projects. This information enables them to manage their projects more efficiently. This effect generates an advantage, with an added value in the capital markets, to direct investments relative to portfolio investments.

There are, however, costs to direct investments. We specify two types of costs. The first type reflects the initial cost that an FDI investor has to incur in order to acquire the expertise to manage the project directly. This cost is exogenously given in the model. The second type, an informationbased cost, is derived endogenously in the model. It results from the possibility that investors need to sell their investments before maturity because they face liquidity shocks. In such circumstances, the price they can get will be lower if they have more information on the economic fundamentals of the investment project. This is because when potential buyers know that the seller has more information, they may suspect that the sale results from bad information on the prospects of the investment, and will thus be willing to pay a lower price. Thus, if they invest directly, the investors bear the cost of getting a lower price if and when they are forced to sell the project before maturity.

Our model, therefore, describes a key trade off between management efficiency and liquidity. ${ }^{5}$ Both sides of this trade off are driven by the effect of asymmetric information, which comes with control. When they invest directly, investors get more information about the fundamentals of the investment, and thereby can manage the project more efficiently, than their portfolio-investors counterparts. However, this also generates a "lemons" type problem when they try to sell the investment before maturity (Akerlof (1970)). Therefore, this superior information effect reduces the price they can get when they are forced to sell the project prematurely.

This trade off between efficiency and liquidity has strong roots in existing empirical evidence. The idea that control increases efficiency and value of the firm, which constitutes one side of the trade off, is supported empirically by two recent papers in the international finance literature. The first paper - by Perez-Gonzalez (2005) - shows that after a foreign investor establishes a position that is greater than $50 \%$ of the firm's shares, the firm's productivity, computed using data on future earnings, improves. The second paper - by Chari, Ouimet, and Tesar (2005) - demonstrates the

\footnotetext{
${ }^{5}$ Note that the interpretation of the word "liquidity" here is different from the one in the phrase "liquidity shock". Here, "liquidity" means that when they invest in FDI, investors will face a less liquid market when they want to sell, in the sense that they will get a lower price. A "liquidity shock" means that an investor is facing a shock that forces her to liquidate the investment.
} 
positive response in the stock market to the establishment of control (defined, again, as more than $50 \%$ ownership). Since having more than $50 \%$ ownership is the ultimate indication for control, these two papers provide clear evidence on the link between control and value, which is a basic premise of our paper. It should be noted, however, that large shareholders can achieve effective control in many cases by holding a block that is much smaller than $50 \%$ of the firm. This has been noted in the finance literature by Shleifer and Vishny (1986), Bolton and von Thadden (1998) and others. Going back to our basic premise, this implies that the value of the firm may increase with ownership concentration even when the controlling shareholder has a block that is smaller than $50 \%$. Such evidence is provided by Wruck (1989) and by Hertzel and Smith (1993). This is much in line with our focus on the trade off between FDI and FPI, since many FDI investments exhibit blocks that are much smaller than $50 \%$.

The other side of the trade off - the idea that the sale of shares by control holders generates a larger price impact than a sale by other investors - can be supported by two strands in the finance literature. First, it has been shown that the sale of stocks by large blockholders has a bigger downward effect on the price than sales of stocks by other investors. For example, see: Mikkelson and Partch (1985), Holthausen, Leftwich, and Mayers (1990), and Chan and Lakonishok (1995). Following the logic above, this result may well apply to the basic premise of our paper, as large blockholders probably have more control over the firms' management. Second, perhaps the best evidence on the price impact of sale in the presence of control can be obtained by looking at what happens when the firm sells its own shares. After all, the firm has ultimate control over its operations, and thus this type of transaction is expected to suffer most from asymmetric information between the seller (firm) and potential buyers. Indeed, the finance literature has documented the large decrease in price following an announcement by the firm that it is going to sell new equity (a seasoned equity offering, SEO). For example, see: Masulis and Korwar (1986) and Korajczyk, Lucas, and MacDonald (1991). ${ }^{6}$

\footnotetext{
${ }^{6}$ This obviously also applies to the well-known underpricing phenomena in firms' initial public offerings (IPOs), although here we do not observe the price before the offering, and thus cannot compare it with the offering price. Still, an interesting piece of evidence from IPOs that supports the premise in our model is that when entrepreneurs keep more shares of the firm after the IPO, the price they get for the IPO is higher (see Downes and Heinkel (1982)). Since entrepreneurs undoubtedly control their firms, they are expected to have private information on them, and thus the fact that they choose to sell fewer shares sends a positive signal that increases the price.
} 
A main implication of the trade off between efficiency and liquidity described in our paper is that investors with high (low) expected liquidity needs are more likely to choose less (more) control. This is because investors with high expected liquidity needs are affected more by the low sale price associated with control, whereas those with low expected liquidity needs are affected more by the efficiency in management. As a result, in equilibrium, assets under control are less likely to be liquidated prematurely. This is consistent with evidence provided by Hennart, Kim, and Zeng (1998) and other papers in the management literature. They show that international investors are much more likely to exit from joint ventures than from fully owned investments, which clearly exhibit more control. In the context of our paper, since FDI exhibit more control than FPI, FDI are expected to be liquidated less often. This is consistent with empirical evidence cited in the beginning of our paper. It also contributes to the low volatility of net FDI inflows relative to net FPI inflows, which is one of the key observations motivating our analysis.

Interestingly, these effects are magnified by asymmetric-information externalities among investors with high expected liquidity needs: when fewer investors of their type choose direct investments, the re-sale price of these investments will decrease, and the incentive of each investor of this type to choose these investments will decrease. These externalities generate multiple equilibria for some parameter values in our model, where some equilibria are characterized by more FDI than others. We show in the paper that when such multiplicity exists, the host country benefits more under the equilibrium that exhibits more FDI.

Of course, equilibrium patterns of investment will vary across countries, depending on the characteristics of investors and on those of the host country itself. In the paper we analyze the patterns of investment as a function of three parameters: the heterogeneity across foreign investors in their expected liquidity needs, the cost of production in the host country, and the level of transparency between owners and managers in the host country (corporate-governance transparency). We employ our results on the last two parameters to derive predictions regarding the differences between developed economies and developing economies. These predictions, which are broadly consistent with the empirical facts described above, are based on the hypotheses that developed countries have higher costs of production and higher levels of transparency than developing countries.

Some papers in the literature develop ideas related to the ideas in the current paper. Albuquerque (2003) develops a model aimed at explaining the differences between the volatility of direct 
investments and the volatility of portfolio investments. His paper relies on expropriation risks and the inalienability of direct investments, and thus is different from the information-based mechanism developed here.

Other papers in the literature use the asymmetric information hypothesis to address different issues related to FDI. In Froot and Stein (1991), Klein and Rosengren (1994), and Klein, Peek and Rosengren (2002), the hypothesis is that FDI is information intensive, and thus FDI investors, who know more about their investments than outsiders, face a problem in raising resources for their investments. Gordon and Lans Bovenberg (1996) assume asymmetric information between domestic investors and foreign investors to explain the home bias phenomenon. Razin, Sadka and Yuen (1998) explain the pecking order of international capital flows with a model of asymmetric information. Finally, Razin and Sadka (2003) analyze the gains from FDI when foreign direct investors have superior information on the fundamentals of their investment, relative to foreign portfolio investors. Importantly, none of these papers analyzes the effects of asymmetric information on the liquidity of FDI and FPI, which is a major factor in the trade off developed in the current paper.

Finally, although we write this paper in the context of international capital flows, we believe the mechanism we suggest here is more general, and can serve to analyze the trade off between direct investments and portfolio investments, or between management efficiency and liquidity, in other contexts. ${ }^{7}$ In a related paper, Bolton and von-Thadden (1998) analyze a trade off between direct investments and portfolio investments. Their model, however, is not based on the differences in information that each one of these investments provides. Kahn and Winton (1998) and Maug (1998) study models where the information held by institutional investors does not always improve the value of the firm, as institutional investors might use this information to make trading profits instead of to improve firm performance. These models do not look, however, at the decision of the investors on whether to acquire information when they might get liquidity shocks. Our paper also touches on other issues that have been discussed in the finance literature. Admati and Pfleiderer (1991) discuss the incentive of traders to reveal the fact that they are trading for liquidity reasons and not because of bad information. Admati and Pfleiderer (1988) and Foster and Viswanathan

\footnotetext{
${ }^{7}$ The model is especially relevant in the context of international flows because there is a strong empirical evidence on the composition and volatility of international flows, which can be explained by our trade off.
} 
(1990) point to the existence of externalities between traders who trade for liquidity reasons.

The remainder of this paper is organized as follows: Section 2 presents the model. In Section 3, we study the basic trade off between direct investments and portfolio investments. Section 4 analyzes the patterns of investments obtained in equilibrium for different parameter values. In Section 5 , we extend the model to allow for different levels of transparency, and study the effect of transparency on the equilibrium outcomes. Section 6 concludes, and highlights additional implications of our model. Proofs are relegated to the appendix.

\section{The Model}

A small economy is faced by a continuum $[0,1]$ of foreign investors. Each investor has an opportunity to invest in one investment project. Investment can occur in two forms. The first form is a direct investment. The second form is a portfolio investment. The difference between the two forms of investment, in our model, is that a direct investor will effectively act like a manager, whereas in case of a portfolio investment, the investor will not be the manager, and the project will be managed by an "outsider". We assume that investors are risk neutral, and thus each investor chooses the form of investment that maximizes her ex-ante expected payoff.

There are three periods of time: 0,1 , and 2 . In period 0 , each investor decides whether to make a direct investment or a portfolio investment. In period 2, the project matures. The payoff from the project is denoted as $R$, where $R$ is given by:

$$
R=(1+\varepsilon) k-\frac{1}{2} A k^{2}
$$

Here, $\varepsilon$ denotes a random productivity factor (technology shock) that is independently realized for each project in period $1 ; k$ is the level of capital input invested in the project in period 1 , after the realization of $\varepsilon$. We assume that $\varepsilon$ is distributed between -1 and 1 , according to a cumulative distribution function $G(\cdot)$, and a density function $g(\cdot)=G^{\prime}(\cdot)$. We also assume that $E(\varepsilon)=0 .{ }^{8}$

\footnotetext{
${ }^{8}$ Our results hold for more general specifications of the distribution of $\varepsilon$. We use this specification merely to simplify the exposition.
} 


\subsection{Management and Efficiency}

In period 1, after the realization of the technology shock, the manager of the project observes $\varepsilon$. Thus, if the investor owns the project as a direct investment, she observes $\varepsilon$, and chooses $k$, so as to maximize the payoff. The chosen level of $k$ will then be equal to $k^{*}(\varepsilon)$, which is given by:

$$
k^{*}(\varepsilon)=\frac{1+\varepsilon}{A} .
$$

Thus, the ex-ante expected payoff from a foreign direct investment if it is held until maturity is given by:

$$
E\left(\frac{(1+\varepsilon) \cdot(1+\varepsilon)}{A}-\frac{1}{2} A\left(\frac{1+\varepsilon}{A}\right)^{2}\right)=\frac{E\left((1+\varepsilon)^{2}\right)}{2 A} .
$$

In case of a portfolio investment, the owner is not the manager, and thus she does not observe $\varepsilon$. In this case, the manager follows earlier instructions as for the level of $k$. A possible rationale behind this sequence of firm decisions, whereby the level of capital input $k$ is determined ex ante, has to do with a potential agency problem between the owner and the manager (who is responsible for making these decisions). Loosely speaking, the latter is not exclusively interested in the net worth of the firm as is the former. For example, with no explicit instructions at hand, the manager may wish to set $k$ at the highest possible level in order to gain power and financial rewards. As a result, when the owner does not have information about the firm's productivity, she will have to set investment guidelines for the manager (who knows more about $\varepsilon$ than she does) so as to protect her own interests. ${ }^{9}$

The ex-ante instruction is chosen by the owner so as to maximize the expected return absent any information on the realization of $\varepsilon$, and is based on the ex ante mean of $\varepsilon$ : 0 . Thus, the

\footnotetext{
${ }^{9}$ The argument, according to which the manager wishes to make larger investments and build an empire is common in the corporate finance literature (see: Jensen (1986)). In such a case, if the owner cannot verify the information that the manager had at the time of the decision, she will not be able to prove that the manager acted to maximize his own objective function. As a result, a contract that instructs the manager to maximize the value of the firm given his information will not be enforceable.

The agency problem is not modelled explicitly here because we want to focus instead on its implications for the trade off between direct investments and portfolio investments. What we do, however, capture in our model is the spirit of the agency problem, and the inefficiency associated with the fact that the owner of the project is not the manager.
} 
manager will be instructed to choose $k=k^{*}(0)=\frac{1}{A} \cdot{ }^{10}$ Then, the ex-ante expected payoff from a portfolio investment if it is held until maturity is:

$$
E\left(\frac{(1+\varepsilon)}{A}-\frac{1}{2 A}\right)=\frac{E(1+2 \varepsilon)}{2 A}=\frac{1}{2 A} .
$$

Comparing (3) with (4), we see that if the project is held until maturity, it yields a higher payoff as a direct investment than as a portfolio investment. This result reflects the efficiency that results from a hands-on management style in the case of a direct investment.

There are, however, costs to direct investments. We specify two types of costs. The first type, reflects the initial cost that an FDI investor has to incur in order to acquire the expertise to manage the project directly. We denote this cost, which is exogenously given in the model, by $c$. We simply assume that an investor who chooses FDI over FPI has to pay the fixed cost at time 0 .

The second type, an information-based cost, is derived endogenously in the model. It results from the possibility of liquidity shocks occurring in period 1.

\section{$2.2 \quad$ Liquidity Shocks and Resale Prices}

In period 1 , before the value of $\varepsilon$ is observed, the owner of the project might get a liquidity shock. With the realization of a liquidity shock, the investor is forced to sell the project immediately, i.e., in period 1. This feature of the model is similar to the preference-shock assumption made by Diamond and Dybvig (1983): an investor who is subject to a liquidity shock derives her utility only from period-1 consumption. If, however, she is not subject to a liquidity shock, she derives her utility from period-2 consumption. As a result, an investor who is subject to a liquidity shock is forced to sell the project in period 1, because she cannot afford to wait and collect the payoff from the project in period 2 .

We denote by $\lambda$ the probability of liquidity shocks. We assume that there are two types of foreign investors. Proportion $\frac{1}{2}$ of the investors have high expected liquidity needs, and proportion $\frac{1}{2}$ have low expected liquidity needs. Formally, we assume that the first type of investors face a

\footnotetext{
${ }^{10}$ The current specification, according to which the owner of a portfolio investment receives no information on the realization of $\varepsilon$, and thus instructs the manager to choose $k$ according to the ex-ante mean of $\varepsilon$ is simple and is intended to capture the spirit of the inefficiency. The result will hold under more general specifications. For example, in Section 5 we study an extension, in which the owner observes $\varepsilon$, but only with some probability.
} 
liquidity need with probability $\lambda_{H}$, whereas the second type face a liquidity need with probability $\lambda_{L}$. For simplicity, we assume that $1>\lambda_{H}>\frac{1}{2}>\lambda_{L}>0$, and that $\lambda_{H}+\lambda_{L}=1 .{ }^{11}$ Investors know their type ex ante, but this is their own private information.

There is, however, also a possibility that an investor will liquidate a project in period 1 even if there is no liquidity shock. This can happen if and only if the initial investor observes a relatively low realization of $\varepsilon$. In such a case she does have superior information over the buyer, and can exploit it. Because portfolio investors do not observe $\varepsilon$ in period 1 , only direct investors sell their investment project at that time when a liquidity shock is absent. ${ }^{12}$ Because all kinds of sales occur simultaneously in period 1, buyers do not know the reason for a sale of any individual project. They know, however, whether the investment project is sold by a direct investor or by a portfolio investor. Because only direct investment projects are sold due to low productivity shocks, the price that direct investors can get when they try to sell the project in period 1 will be lower than the price obtained by portfolio investors. This generates a cost of the second type to FDI.

To evaluate this cost, we now derive the price that a direct investor gets if she sells the project in period 1. The price is equal to the expected value of the project from the point of view of the buyer, given that the buyer knows that the owner is trying to sell, and given that she does not know the reason for the sale. We denote the threshold level of $\varepsilon$, under which the direct investor is selling the project in absence of a liquidity shock by $\underline{\varepsilon}_{D}$. Also, we denote by $\lambda_{D}$ the probability, as perceived by the market, that an FDI investor gets a liquidity shock. Both $\underline{\varepsilon}_{D}$ and $\lambda_{D}$ will be endogenously determined in equilibrium. Given that the FDI owner sells her project, the buyer thinks that with probability $\left(1-\lambda_{D}\right) G\left(\underline{\varepsilon}_{D}\right)$ the owner is selling the project due to a low realization of $\varepsilon$, and with probability $\lambda_{D}$ she sells the project because of a liquidity shock.

If the project is sold due to a liquidity shock, that is, before the initial owner observes $\varepsilon$ (recall that liquidity shocks are realized before productivity shocks), the value of $\varepsilon$ is not recorded in the firm before the sale. Therefore, the buyer does not know the value of $\varepsilon$. However, if the project is sold for low-profitability reasons, the new owner will know the value of $\varepsilon$ after the sale. ${ }^{13}$

\footnotetext{
${ }^{11}$ Note that our results hold in a more general setting, that is, for any $\lambda_{H}>\lambda_{L}$.

${ }^{12}$ This is again a result of our specification, in which the owner of a portfolio investment receives no information on the realization of $\varepsilon$ in period 1. This assumption will be relaxed in Section 5 .

${ }^{13}$ Note that this is just a technical assumption regarding the procedures of the sale. It does not qualitatively affect the results.
} 
Using Bayes' rule, the period 1 price that the direct investor gets for the project is given by:

$$
P_{1, D}=\frac{\left(1-\lambda_{D}\right) \int_{-1}^{\varepsilon_{D}} \frac{(1+\varepsilon)^{2}}{2 A} g(\varepsilon) d \varepsilon+\lambda_{D} \int_{-1}^{1} \frac{1+2 \varepsilon}{2 A} g(\varepsilon) d \varepsilon}{\left(1-\lambda_{D}\right) G\left(\underline{\varepsilon}_{D}\right)+\lambda_{D}} .
$$

The initial owner, in turn, sets the threshold level $\underline{\varepsilon}_{D}$, such that given $P_{1, D}$, when observing $\underline{\varepsilon}_{D}$, she is indifferent between selling, or not selling, the project. This yields the following equation:

$$
P_{1, D}=\frac{\left(1+\underline{\varepsilon}_{D}\right)^{2}}{2 A}
$$

Thus, equations (5) and (6) simultaneously determine $P_{1, D}$ and $\underline{\varepsilon}_{D}$ as a function of the marketperceived probability $\lambda_{D}$. Proposition 1 characterizes $\underline{\varepsilon}_{D}\left(\lambda_{D}\right)$ and $P_{1, D}\left(\lambda_{D}\right)$.

Proposition 1 (i) For every $0 \leq \lambda_{D} \leq 1$, there is a unique solution to $\underline{\varepsilon}_{D}$ between -1 and 0 , where $\underline{\varepsilon}_{D}\left(\lambda_{D}\right)$ is monotonically increasing in $\lambda_{D}$.

(ii) For every $0 \leq \lambda_{D} \leq 1$, there is a unique solution to $P_{1, D}$ between 0 and $\frac{1}{2 A}$, where $P_{1, D}\left(\lambda_{D}\right)$ is monotonically increasing in $\lambda_{D}$.

The intuition that $\underline{\varepsilon}_{D}\left(\lambda_{D}\right)$ and $P_{1, D}\left(\lambda_{D}\right)$ are increasing in $\lambda_{D}$ is as follows: when $\lambda_{D}$ is high, the buyer thinks that the probability that an early sale results from a liquidity shock (and not from a bad realization of the productivity parameter) is also high. Consequently, the resale price of the project in period 1 is high as well. This means that FDI investors sell their projects more often (that is, under a higher threshold $\underline{\varepsilon}_{D}$ ). An implication is that investors have a greater incentive to choose FDI in period 0 when the market participants think that investors with high liquidity needs choose FDI. This externality plays an important role in the next section where we derive the equilibrium allocation and market prices.

Another noteworthy part of the proposition is that $\underline{\varepsilon}_{D}$ is always below 0 , and consequently $P_{1, D}$ is always below $\frac{1}{2 A}$. This feature plays an important role in the comparison between the resale price of FDI and the resale price of portfolio investments. To conduct this comparison, let us characterize the resale price of a portfolio investment project. Essentially, when a portfolio investor sells the project in period 1 , everybody knows she does it because of a liquidity shock. Thus, the price she gets for the project is given by:

$$
P_{1, P}=\int_{-1}^{1} \frac{1+2 \varepsilon}{2 A} g(\varepsilon) d \varepsilon=\frac{1}{2 A}
$$


Now, we can see that the resale price of a direct investment in period 1 is always lower than the resale price of a portfolio investment in that period. The intuition is that if a direct investor prematurely sells the investment project, the market price must reflect the possibility that the sale originates from inside information on low prospects of this investment project.

We can now summarize the essential trade-off between FDI and FPI. A benefit of a direct investment is that it enables the investor to manage the project more efficiently. This increases the return that she gets in case she does not have to sell the project prematurely. However, if a foreign investor ex-ante chooses to hold the project as a direct investment, but sells the project prematurely, she gets a relatively low price. This is because potential buyers perceive that with some probability the project is sold due to negative inside information about the prospects of the investment. Thus, the additional information associated with a direct investment is not necessarily beneficial. In addition, investing directly entails a fixed cost $c$. With such trade off between FDI and FPI in mind, investors choose the type of investment that maximizes their ex ante expected payoff. We now turn to study this choice.

\section{Ex-Ante Choice between FDI and FPI}

\subsection{Expected Value of FDI}

With probability $\lambda_{i}$, investor $i$ gets a liquidity shock, and sells the project in period 1 . (Note that this probability can be different from $\lambda_{D}$, the probability perceived by the market.) The market price is:

$$
P_{1, D}\left(\lambda_{D}\right)=\frac{\left(1+\underline{\varepsilon}_{D}\left(\lambda_{D}\right)\right)^{2}}{2 A}
$$

With probability $1-\lambda_{i}$, the investor does not get a liquidity shock. She sells the project if the realization of $\varepsilon$ is below $\underline{\varepsilon}_{D}\left(\lambda_{D}\right)$, but she does not sell it if the realization of $\varepsilon$ is above $\underline{\varepsilon}_{D}\left(\lambda_{D}\right)$. Recall that $\left(\underline{\varepsilon}_{D}\left(\lambda_{D}\right)\right.$ is determined by equations (5) and (6)). Therefore, the expected payoff, in the state of no liquidity shock is:

$$
\int_{-1}^{\underline{\varepsilon}_{D}\left(\lambda_{D}\right)} \frac{\left(1+\underline{\varepsilon}_{D}\left(\lambda_{D}\right)\right)^{2}}{2 A} g(\varepsilon) d \varepsilon+\int_{\underline{\varepsilon}_{D}\left(\lambda_{D}\right)}^{1} \frac{(1+\varepsilon)^{2}}{2 A} g(\varepsilon) d \varepsilon .
$$


In addition, a direct investor has to incur a fixed cost of $c$. Thus, the ex-ante expected payoff for a direct investor, as a function of $\lambda_{i}, \lambda_{D}$ and $A$, is given by:

$$
\begin{aligned}
E V_{\text {Direct }}\left(\lambda_{i}, \lambda_{D}, A\right)= & \left(1-\lambda_{i}\right)\left[\int_{-1}^{\underline{\varepsilon}_{D}\left(\lambda_{D}\right)} \frac{\left(1+\underline{\varepsilon}_{D}\left(\lambda_{D}\right)\right)^{2}}{2 A} g(\varepsilon) d \varepsilon+\int_{\underline{\varepsilon}_{D}\left(\lambda_{D}\right)}^{1} \frac{(1+\varepsilon)^{2}}{2 A} g(\varepsilon) d \varepsilon\right] \\
& +\lambda_{i} \cdot \frac{\left(1+\underline{\varepsilon}_{D}\left(\lambda_{D}\right)\right)^{2}}{2 A}-c .
\end{aligned}
$$

\subsection{Expected Value of FPI}

When the investor holds the investment as a portfolio investment, with probability $\lambda_{i}$, she receives a liquidity shock, and sells the project in period 1 . Then, the selling price is:

$$
P_{1, P}=\frac{1}{2 A}
$$

With probability $1-\lambda_{i}$, the investor does not receive a liquidity shock. Then, her expected payoff is:

$$
\frac{E(1+2 \varepsilon)}{2 A}=\frac{1}{2 A}
$$

Therefore, the ex ante expected payoff from a portfolio investment is given by:

$$
E V_{\text {Portfolio }}(A)=\frac{1}{2 A}
$$

\subsection{FDI vs. FPI}

We define the difference between the expected value of FDI and the expected value of FPI as follows:

$$
\operatorname{Diff}\left(\lambda_{i}, \lambda_{D}, A\right) \equiv E V_{\text {Direct }}\left(\lambda_{i}, \lambda_{D}, A\right)-E V_{\text {Portfolio }}(A) .
$$

Then, investor $i$ will choose FDI when $\operatorname{Diff}\left(\lambda_{i}, \lambda_{D}, A\right)>0$; will choose FPI when $\operatorname{Diff}\left(\lambda_{i}, \lambda_{D}, A\right)<$ 0; and will be indifferent between the two (i.e., may choose either FDI or FPI) when $\operatorname{Diff}\left(\lambda_{i}, \lambda_{D}, A\right)=$ 0.

Proposition 2 studies the effect of different parameters on the function $\operatorname{Diff}\left(\lambda_{i}, \lambda_{D}, A\right)$, and thus on the choice between the two forms of investment. 
Proposition 2 Investor $i$ is more likely to choose FDI when:

(i) The fixed cost c of FDI is lower.

(ii) The cost of production $A$ in the host country is lower.

(iii) The probability of getting a liquidity shock $\lambda_{i}$ is lower.

(iv) The market-perceived probability $\lambda_{D}$ of a liquidity shock for FDI investors is higher.

The result in Part (i) is expected: investors are less likely to choose FDI when the fixed cost they have to incur in order to set the direct investment up is higher. Part (ii) of the proposition says that when the cost of production $A$ in the host country is higher, investors are less likely to choose FDI. The intuition behind this result is that when the cost of production increases, the overall profitability of investment projects decreases, and this makes it less beneficial to incur the additional fixed cost associated with FDI. Part (iii) of the proposition means that investors with lower ex ante liquidity needs are more likely to choose direct investments. This is because these investors expect to benefit more from the long-term efficiency associated with FDI, and to suffer less from the lower short-term price of this form of investment. Finally, Part (iv) of the proposition states that when the probability $\lambda_{D}$ that is assessed by the market to a liquidity shock of FDI investors increases, investors are more likely to choose FDI. The intuition is related to the fact that the resale price of FDI increases in $\lambda_{D}$ (see Proposition 1). This makes direct investments more attractive relative to portfolio investments.

\section{FDI and FPI in Equilibrium}

\subsection{Equilibrium Outcomes}

So far, we analyzed the equilibrium choice of investors between the two types of investment given the market-perceived probability $\lambda_{D}$. To complete the definition of equilibrium, we need to specify how $\lambda_{D}$ is determined. Assuming that rational expectations hold in the market, $\lambda_{D}$ has to be consistent with the equilibrium choice of investors between FDI and FPI. Thus, it is given by the following equation:

$$
\lambda_{D}=\frac{\lambda_{H} \cdot \lambda_{H, F D I}+\lambda_{L} \cdot \lambda_{L, F D I}}{\lambda_{H, F D I}+\lambda_{L, F D I}}
$$

Here, $\lambda_{H, F D I}$ is the proportion of $\lambda_{H}$ investors who choose FDI in equilibrium and $\lambda_{L, F D I}$ is the proportion of $\lambda_{L}$ investors who choose FDI in equilibrium. 
It should be noted that if all investors choose FPI in equilibrium, $\lambda_{D}$ cannot be defined by the above equation. This is because in such an equilibrium, investors are not expected to choose FDI at all. Thus, we need to make an off-equilibrium assumption to determine $\lambda_{D}$ in case that an investor diverges from that equilibrium and chooses to hold a direct investment. Since $\lambda_{L}$ investors have greater incentives to hold direct investments than $\lambda_{H}$ investors (see Proposition 2), we assume that, in an equilibrium where all investors choose FPI, if an investor diverges and invests in FDI, the market assesses a probability of $\lambda_{L}$ to the event that this investor had a liquidity shock. Note that this off-equilibrium assumption is not important for our results.

We now turn to characterize the equilibrium outcomes. A first crucial result is that there cannot be an equilibrium where some $\lambda_{H}$ investors choose FDI, while some $\lambda_{L}$ investors choose FPI. To see this, note that such an equilibrium would imply that $\operatorname{Diff}\left(\lambda_{H}, \lambda_{D}, A\right) \geq 0$ while $\operatorname{Diff}\left(\lambda_{L}, \lambda_{D}, A\right) \leq 0$. However, this is a contradiction to the result that $\operatorname{Diff}\left(\lambda_{i}, \lambda_{D}, A\right)$ is strictly decreasing in $\lambda_{i}$, which is shown in the proof of Proposition 2. Thus, only five cases can potentially be observed in equilibrium. These are summarized as follows:

Case 1: All investors choose FDI.

Case 2: $\lambda_{L}$ investors choose FDI; $\lambda_{H}$ investors split between FDI and FPI.

Case 3: $\lambda_{L}$ investors choose FDI; $\lambda_{H}$ investors choose FPI.

Case 4: $\lambda_{L}$ investors split between FDI and FPI; $\lambda_{H}$ investors choose FPI.

Case 5: All investors choose FPI.

In describing the equilibrium outcomes below, we will often refer to these cases. It is worth noting that as we move from Case 1 to Case 5, the amount of FDI in the economy decreases, while the amount of FPI increases. Note also that only in cases 2, 3, and 4, FDI and FPI coexist in the economy. Also, among these, Case 3 exhibits the largest difference between expected liquidity needs for a representative FDI investor and those for a representative FPI investor.

Proposition 3 provides a full characterization of the equilibrium outcomes as a function of two parameters: $\lambda_{H}$ and $A$. The value of $\lambda_{H}$ reflects the probability that investors with high expected liquidity needs will get a liquidity shock. Since we assumed that $\lambda_{L}+\lambda_{H}=1$, we know that the value of $\lambda_{H}$ also indirectly determines the value of $\lambda_{L}$ (which reflects the probability that investors with low expected liquidity needs will get a liquidity shock). Thus, our interpretation is that an increase in $\lambda_{H}$ reflects an increase in the heterogeneity across investors. The parameter $A$ describes 


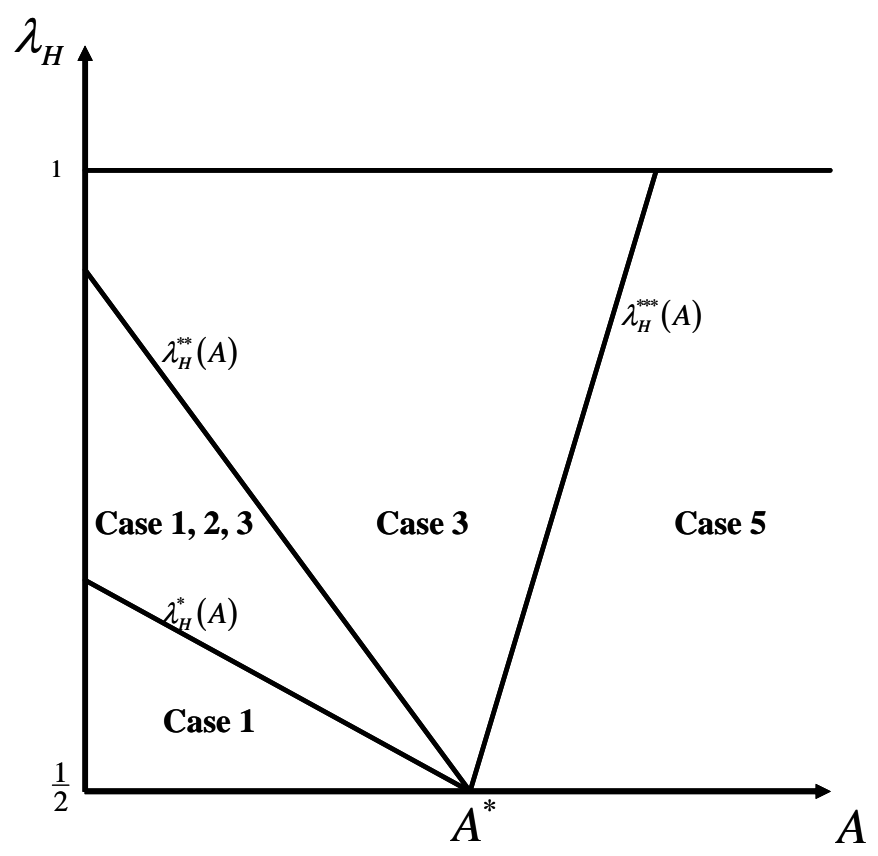

Figure 1: Equilibrium Outcomes

the cost of production. An increase in $A$ thus reduces the profitability of the investment project. A key in the characterization of equilibrium outcomes will be the threshold value $A^{*}$, which is defined by the following equation:

$$
\operatorname{Diff}\left(\frac{1}{2}, \frac{1}{2}, A^{*}\right)=0
$$

Proposition 3 (i) For any $A<A^{*}$, there exist $\lambda_{H}^{*}(A)$ and $\lambda_{H}^{* *}(A)$, where $\frac{1}{2}<\lambda_{H}^{*}(A)<\lambda_{H}^{* *}(A)<1$ and both $\lambda_{H}^{*}(A)$ and $\lambda_{H}^{* *}(A)$ are strictly decreasing in $A$. Then, when $\frac{1}{2}<\lambda_{H}<\lambda_{H}^{*}(A)$, the only possible equilibrium is Case 1; when $\lambda_{H}^{*}(A)<\lambda_{H}<\lambda_{H}^{* *}(A)$, the possible equilibria are Case 1, Case 2, and Case 3; and when $\lambda_{H}^{* *}(A)<\lambda_{H}<1$, the only possible equilibrium is Case 3.

(ii) For any $A>A^{*}$, there exists $\lambda_{H}^{* * *}(A)$, where $\frac{1}{2}<\lambda_{H}^{* * *}(A) \leq 1$ and $\lambda_{H}^{* * *}(A)$ is strictly increasing in $A$. Then, when $\frac{1}{2}<\lambda_{H}<\lambda_{H}^{* * *}(A)$, the only possible equilibrium is Case 5; and when $\lambda_{H}^{* * *}(A)<\lambda_{H}<1$, the only possible equilibrium is Case $3 .^{14}$

Figure 1 provides a simple illustration of the equilibrium characterization.

\footnotetext{
${ }^{14}$ For brevity, we do not characterize here the equilibrium outcomes for the specific values: $A=A^{*} ; \lambda_{H}=\lambda_{H}^{*}$; $\lambda_{H}=\lambda_{H}^{* *}$; and $\lambda_{H}=\lambda_{H}^{* * *}$.
} 
We would like to discuss four features of the equilibrium outcomes. These are organized in four corollaries below.

Corollary 1: If FDI and FPI coexist in equilibrium, then the expected liquidity needs of FDI investors are lower, on average, than the expected liquidity needs of FPI investors.

As noted above, the only possible cases in equilibrium, where FDI and FPI coexist, are cases 2, 3, and 4. In all these cases, liquidity shocks are more common among FPI investors than among FDI investors. The intuition is simple: investors with high expected liquidity needs care less about the long-term efficiency of FDI, and care more about the short-term price. Thus, they have a higher tendency to invest in FPI. On the other hand, investors with low expected liquidity needs tend to prefer FDI. This result is consistent with the casual observation that FDI investors are often large and stable multinational companies with low expected liquidity needs, whereas FPI investors (such as global mutual funds) are, on average, more vulnerable to liquidity shocks. This result contributes to the high withdrawal ratio of FPI relative to FDI, which can account for the empirically-observed higher volatility of net FPI inflows.

Corollary 2: As the cost of production in the host country increases, there will be more FPI and less FDI in equilibrium.

We can see this clearly by looking at Figure 1 . As the level of $A$, which represents the cost of production in the host country, increases, equilibrium outcomes change from Case 1, via cases 2 and 3, to Case 5 - i.e., they gradually exhibit more FPI and less FDI. Since $A$ represents the cost of production, we expect developed countries to have higher levels of $A$. Thus, our model predicts that developed countries will attract more FPI, whereas developing countries will attract more FDI. This is indeed consistent with empirical evidence. The intuition is the following: developed countries have higher costs of production, and thus lower profitability of investment projects. Thus, in these countries, it is less beneficial to pay the fixed costs associated with establishing an FDI investment.

Corollary 3: As the heterogeneity among investors increases, a separating equilibrium - with a large difference between the withdrawal rate of FPI and the withdrawal rate of FDI-becomes more likely.

This result can also be seen in Figure 1. When $A<A^{*}$, an increase in $\lambda_{H}$ shifts the equilibrium outcome from Case 1, which is a pooling equilibrium, to Case 3, which is a separating equilibrium 
with a large difference between the withdrawal rates of the two types of investment. When $A>A^{*}$, an increase in $\lambda_{H}$ shifts the equilibrium outcome from Case 5, which is a pooling equilibrium, to Case 3. The implication is that a high level of heterogeneity among investors causes them to be attracted to different types of investment, and leads to observed differences in withdrawal rates and volatility between FDI and FPI.

Corollary 4: There is a region of the fundamentals with multiple equilibria.

As noted in the proposition, multiple equilibria exist when $A<A^{*}$ and $\lambda_{H}^{*}(A)<\lambda_{H}<\lambda_{H}^{* *}(A)$. In this region, Case 1, Case 2 and Case 3 are possible equilibria. The reason for the multiplicity is the existence of externalities among $\lambda_{H}$ investors. A $\lambda_{H}$ investor benefits from having other investors of her type investing in the same type of investment. This is because, then, when she tries to sell the project, the price will not be that low since the market knows that the sale is very likely to be driven by a liquidity shock. As a result, when all $\lambda_{H}$ investors invest in portfolio investments, an individual $\lambda_{H}$ investor would like to do the same thing in order to avoid the low price of a direct investment in case she needs to sell (given that she needs to sell quite often). Similarly, when all $\lambda_{H}$ investors invest in direct investments, an individual $\lambda_{H}$ investor would like to invest in a direct investment as well. This multiplicity may generate jumps from an equilibrium with a lot of direct investments to an equilibrium with much less direct investments. This may explain why some countries have more direct investments than other countries with similar characteristics, and why some periods of time are characterized by more direct investments than others. The existence of multiple equilibria also generates interesting welfare implications that will be discussed below.

\subsection{The Probability of Early Withdrawals}

Our analysis thus far showed that whenever the two types of investment coexist in equilibrium, portfolio investors will be more likely than direct investors to get a liquidity shock that forces them to sell their investment in the short term. This, however, does not necessarily imply that FPI's are being reversed more often than FDI's in equilibrium. This is because, in our model, FDI's are being liquidated, not only because of a liquidity shock, but sometimes due to a low realization of $\varepsilon$.

To see this formally, consider Case 3 as an equilibrium. This is the equilibrium where all $\lambda_{H}$ investors choose FPI and all $\lambda_{L}$ investors choose FDI. Thus, it exhibits the largest difference between the expected liquidity needs of FPI investors and those of FDI investors. In this equilibrium, the 
probability of an early withdrawal of FPI is $\lambda_{H}$, whereas the probability of an early withdrawal of FDI is $\lambda_{L}+\left(1-\lambda_{L}\right) G\left(\underline{\varepsilon}_{D}\left(\lambda_{L}\right)\right)$. Analyzing the difference between these two expressions, we can see that there are two opposite effects. On the one hand, since $\lambda_{H}>\lambda_{L}$, the probability of an early withdrawal that is driven by a liquidity shock is greater for FPI than for FDI. But, on the other hand, there is a probability of $\left(1-\lambda_{L}\right) G\left(\underline{\varepsilon}_{D}\left(\lambda_{L}\right)\right)$ that an FDI will be sold at period 1 due to a low realization of $\varepsilon$. This possibility does not exist with an FPI. The condition, under which portfolio investments are being liquidated more often at period 1 than direct investments is then:

$$
\lambda_{H}>\lambda_{L}+\left(1-\lambda_{L}\right) G\left(\underline{\varepsilon}_{D}\left(\lambda_{L}\right)\right) .
$$

Since the left hand side of this condition increases in $\lambda_{H}$ and the right hand side decreases in $\lambda_{H}$ (recall that $\lambda_{H}=1-\lambda_{L}$ ), this condition implies that portfolio investments will be liquidated more often in the short term as long as $\lambda_{H}$ is high enough, or, in other words, as long as the heterogeneity among investors is sufficiently strong.

\subsection{Welfare Analysis}

Our model has interesting welfare implications for the region of parameters with multiple equilibria - i.e., when $A<A^{*}$ and $\lambda_{H}^{*}(A)<\lambda_{H}<\lambda_{H}^{* *}(A)$. As a starting point, we analyze foreign investors' welfare in this region of parameters, given the current framework. Then, we use the result to study the implications for the welfare of residents of the host country, which is the main focus of our welfare analysis.

When $A<A^{*}$ and $\lambda_{H}^{*}(A)<\lambda_{H}<\lambda_{H}^{* *}(A)$, our model has three equilibria: Case 1, Case 2, and Case 3. Our analysis shows that when these three equilibria are possible, Case 1 represents a Pareto improvement over the other two equilibria. To see this, note that under Case $3, \lambda_{H}$ investors choose FPI and gain an expected payoff of $\frac{1}{2 A}$. Similarly, under Case 2, they are indifferent between FDI and FPI, and thus also gain an expected payoff of $\frac{1}{2 A}$. Under Case 1, however, they choose FDI and gain an expected payoff of $E V_{\text {Direct }}\left(\lambda_{H}, \frac{1}{2}, A\right)$. We know that this payoff is greater than $\frac{1}{2 A}$, since $\lambda_{H}$ investors chose to get it rather than to invest in FPI and get $\frac{1}{2 A}$. Thus, $\lambda_{H}$ investors are better off under Case 1, where they benefit from the higher efficiency of FDI. When other equilibria occur in this range of parameters, it is because of a coordination failure: $\lambda_{H}$ investors choose not to invest in FDI because they believe other $\lambda_{H}$ investors will not invest in FDI, and thus will reduce the expected value of this type of investment. 
As for $\lambda_{L}$ investors, in all three equilibria they choose FDI. Under Case 3, their expected payoff is $E V_{\text {Direct }}\left(\lambda_{L}, \lambda_{L}, A\right)$; under Case 1 , it is $E V_{\text {Direct }}\left(\lambda_{L}, \frac{1}{2}, A\right)$; while under Case 2, it gets a value between $E V_{\text {Direct }}\left(\lambda_{L}, \lambda_{L}, A\right)$ and $E V_{\text {Direct }}\left(\lambda_{L}, \frac{1}{2}, A\right)$. Since $E V_{\text {Direct }}\left(\lambda_{i}, \lambda_{D}, A\right)$ is increasing in $\lambda_{D}$, we know that $\lambda_{L}$ investors are better off in Case 1 . The reason is that under Case 1 , all $\lambda_{H}$ investors choose direct investments, and thus the price of direct investments in period 1 is higher.

With these results in mind, let us address the differences in welfare from the point of view of the residents of the host country. Up to this point, the residents of the host country did not have an explicit role in our model. A natural way to introduce them is to assume that they own the local projects initially, and sell them to foreign investors. Let us assume that there is a continuum $[0,1]$ of local residents; each one holds an investment project in period 0. At this time, they sell the projects to the foreign investors. After the sales have taken place, the events in the model are exactly the same as we described before: in period 0, foreign investors choose the form of investment, and in period 1 they make a decision on whether to sell their investments or not. Given this structure, the welfare analysis from the point of view of the local residents boils down to analyzing the price that they get for their projects in period 0.

In period 0 , there are two types of foreign investors buying the investment projects from the residents of the host country: $\lambda_{H}$ investors and $\lambda_{L}$ investors. Since the type of each investor is not observable, in a competitive equilibrium, the price of projects in period 0 will be determined by the lowest between the value that is incurred to $\lambda_{H}$ investors and the value that is incurred to $\lambda_{L}$ investors from holding the project. In our model, this is always the value that is incurred to $\lambda_{H}$ investors. Thus, $\lambda_{L}$ investors capture some of the rent due to their ability to maintain the project for a long time, and $\lambda_{H}$ investors do not capture any rent.

The price that local residents get for the projects in period 0 will then be $\frac{1}{2 A}$ when either Case 2 or Case 3 is the realized equilibrium, and $E V_{\text {Direct }}\left(\lambda_{H}, \frac{1}{2}, A\right)$ when Case 1 is the realized equilibrium. As we showed above, in the region where all three equilibria are possible, the first expression is lower than the second one, meaning that domestic residents get higher prices when Case 1 is the realized equilibrium. This suggests that the host country may benefit from encouraging more investments to be in the form of FDI.

This recommendation, however, should be taken with caution. Our model suggests that intervention to encourage FDI will be beneficial to the host country only in the region of parameters 
where there are multiple equilibria. In this region, portfolio investments are chosen due to a coordination failure, which can be prevented by intervention. In all other regions of parameters, where our model has only one equilibrium, the price that domestic residents get in equilibrium is higher than what they could have gotten under other alternative cases. Thus, in these regions, intervention to encourage more FDI will not be beneficial to the host country. For example, when $A>A^{*}$ and $\frac{1}{2}<\lambda_{H}<\lambda_{H}^{* * *}(A)$, the only equilibrium in our model is Case 5 . In this region of parameters, however, this happens because FDI is not efficient due to high production costs, and thus encouraging FDI will only reduce the price obtained by domestic residents, and will not be beneficial.

\section{The Effect of Transparency}

The trade off between direct investments and portfolio investments in our model is based on asymmetric information. Reducing the degree of asymmetric information via greater transparency can alter the trade off between the two types of investment. In this section we modify our framework to allow for different degrees of transparency. We focus on corporate-governance transparency: the transparency between managers and owners. When this measure of transparency is higher, owners, who do not act as managers, are more informed about the fundamentals of their projects. We will study the effect of transparency on the patterns of investment in equilibrium.

Aside from the theoretical interest in the effect of transparency on the trade off between the two types of investment, the analysis in this section is important because it sheds light on the differences in patterns of investment between developing and developed economies. The conclusions provided in this section are based on the hypothesis that corporate-governance transparency is higher in developed economies than in developing economies.

Assume that in case of a portfolio investment, the owner of the project observes $\varepsilon$ in period 1 with probability $\alpha(0<\alpha<1)$. If this happens, the owner of the project can act as a direct investor: she can instruct the manager to choose the optimal level of $k$, and she can decide to sell the project if the realization of $\varepsilon$ is below a certain threshold. Our interpretation is that a higher $\alpha$ represents a better flow of information between the manager and the owner when the two are not the same person. As a result, a higher $\alpha$ represents a higher level of ex ante transparency. For 
simplicity, in this section, we assume that $c=0$.

The introduction of the parameter $\alpha$ into the model does not change the analysis of direct investments. It only changes the analysis of portfolio investments. When owners of portfolio investments observe $\varepsilon$, they will be able to achieve the same management efficiency as direct investors. Thus, if they don't sell the project in period 1, their investment will yield an expected payoff of: $\frac{E(1+\varepsilon)^{2}}{2 A}$ (see (3)). Additionally, they also may decide to sell the project if the realization of $\varepsilon$ is below a certain level. We denote this threshold level of $\varepsilon$ as $\underline{\varepsilon}_{P}$. Using the same principles as in (5) and (6), we derive the following equation that determines $\underline{\varepsilon}_{P}$ as a function of $\alpha$ and $\lambda_{p}$ (the latter is the probability of a liquidity shock by FPI investors that is perceived by the market):

$$
\frac{1}{2 A} \cdot \frac{\left(1-\lambda_{p}\right) \alpha \int_{-1}^{\varepsilon_{P}\left(\alpha, \lambda_{p}\right)}(1+\varepsilon)^{2} g(\varepsilon) d \varepsilon+\lambda_{p}}{\left(1-\lambda_{p}\right) \alpha G\left(\underline{\varepsilon}_{P}\left(\alpha, \lambda_{p}\right)\right)+\lambda_{p}}=\frac{1}{2 A} \cdot\left(1+\underline{\varepsilon}_{P}\left(\alpha, \lambda_{p}\right)\right)^{2} .
$$

This equation is slightly different from the one implied by (5) and (6), as it considers the fact that a portfolio investor observes $\varepsilon$ with probability $\alpha$. As we show in the appendix, for every $\lambda_{p}$ and $\alpha$ between 0 and 1 , there is a unique solution for $\underline{\varepsilon}_{P}$ between -1 and 0 . As we also show in the appendix, the analysis of the equation reveals that $\underline{\varepsilon}_{P}\left(\alpha, \lambda_{P}\right)$ is increasing in $\lambda_{p}$ and decreasing in $\alpha$. Thus, when the probability of a liquidity shock increases, there is, on average, a smaller problem of asymmetric information between sellers and buyers, and investors will sell their projects under a larger range of parameters. Similarly, when the probability of information being revealed to owners increases, there is, on average, a greater problem of asymmetric information, and investors will sell their projects under a smaller range of parameters. A direct result of the last property is that $\underline{\varepsilon}_{P}(\alpha, x)>\underline{\varepsilon}_{D}(x)$ for every $0<\alpha<1$ - i.e., when the probability of liquidity shocks is the same across the two investments, FPI will be sold at a higher price than FDI.

Following (6), we know that the price of portfolio investments in period 1 will be: $\frac{\left(1+\underline{\varepsilon}_{P}\left(\alpha, \lambda_{p}\right)\right)^{2}}{2 \mathrm{~A}}$. Then, the ex ante expected payoff from a portfolio investment for a $\lambda_{i}$ investor will be:

$$
\begin{aligned}
& \left(1-\lambda_{i}\right)\left[(1-\alpha) \cdot \frac{1}{2 A}+\alpha \int_{-1}^{\underline{\varepsilon}_{P}\left(\alpha, \lambda_{p}\right)} \frac{\left(1+\underline{\varepsilon}_{P}\left(\alpha, \lambda_{p}\right)\right)^{2}}{2 A} g(\varepsilon) d \varepsilon\right. \\
& \left.+\alpha \int_{\underline{\varepsilon}_{P}\left(\alpha, \lambda_{p}\right)}^{1} \frac{(1+\varepsilon)^{2}}{2 A} g(\varepsilon) d \varepsilon\right] \\
& +\lambda_{i} \cdot \frac{\left(1+\underline{\varepsilon}_{P}\left(\alpha, \lambda_{p}\right)\right)^{2}}{2 A} .
\end{aligned}
$$

When $0<\alpha<1$, the basic trade off between direct investments and portfolio investments 
remains the same as in previous sections. On average, direct investments still provide more information to owners. This enables owners to achieve more management efficiency, but also reduces the price they can get when they sell their investments in period 1. As $\alpha$ increases, the differences between the expected payoffs from the two types of investment become smaller.

The analysis of equilibrium outcomes here is similar to the one in previous sections: investors choose between the two types of investment based on expected values, while $\lambda_{D}$ is determined by (11). In addition, here $\lambda_{P}$ also has to be determined by a similar condition, reflecting the idea that the market expectations regarding the probability that FPI investors will get a liquidity shock are consistent with investors' equilibrium strategies. We also need to add another off-equilibrium assumption for the case that all investors choose FDI in equilibrium and an investor diverges from that equilibrium and chooses to hold FPI. Following the logic in Section 4, we assume that in this case the market assesses a probability $\lambda_{H}$ that the portfolio investor receives a liquidity shock. This is because $\lambda_{H}$ investors have greater incentives to hold portfolio investments than $\lambda_{L}$ investors.

In this section, we are mainly interested in the effect of the degree of transparency $\alpha$ on the possible equilibrium outcomes. Proposition 4 characterizes the effect of $\alpha$ on the equilibrium outcomes. It says that increasing $\alpha$ can affect the possible equilibrium outcomes along three different patterns. These patterns are also illustrated in Figure 2.

Proposition 4 As a increases, possible equilibrium outcomes can change in one of the following patterns:

- Case $1 \rightarrow$ Case 1, 2, 3 $\rightarrow$ Case $3 \rightarrow$ Case $4 \rightarrow$ Case 5

- Case1 $\rightarrow$ Case 1, 2, 3 $\rightarrow$ Case 1, 2, 4 $\rightarrow$ Case $4 \rightarrow$ Case 5

- Case $1 \rightarrow$ Case 1, 2, 3 $\rightarrow$ Case 1, 2, 4 $\rightarrow$ Case 1, $5 \rightarrow$ Case 5

Based on Proposition 4 and on Figure 2, we would like to emphasize two effects of the level of transparency on the equilibrium outcomes. These are summarized in the following two corollaries.

Corollary 5: As the level of transparency increases, there will be more FPI and less FDI in equilibrium. 

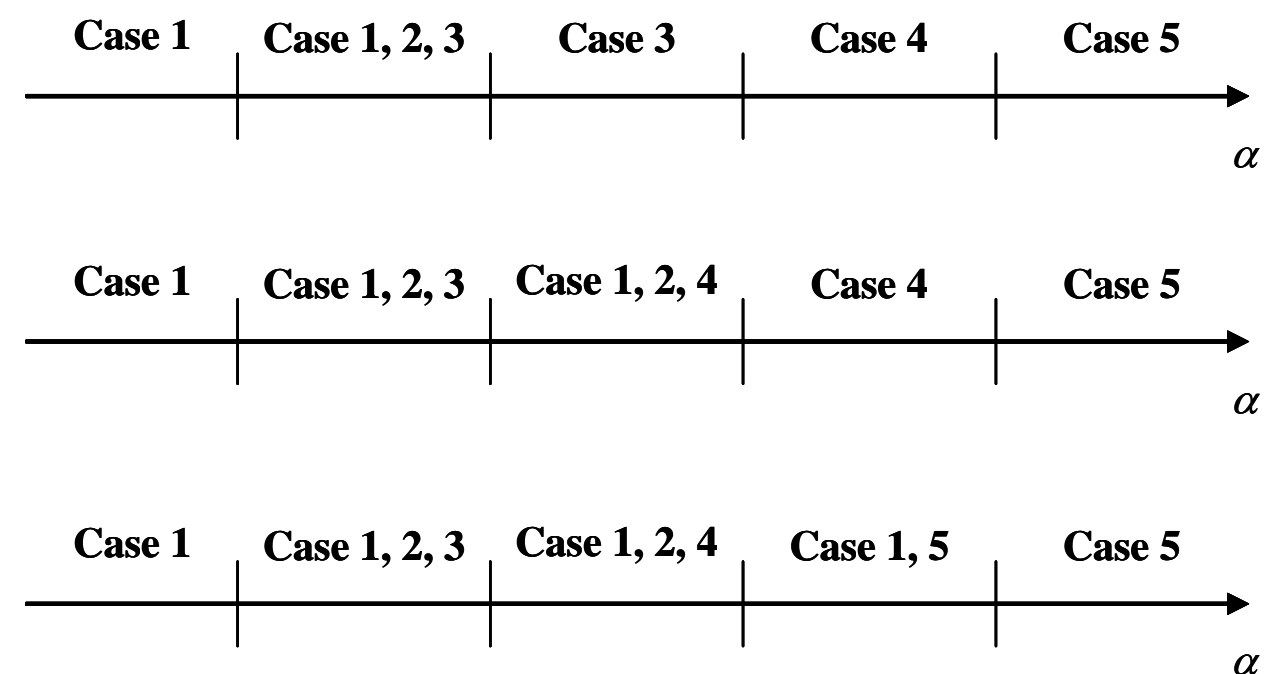

Figure 2: Patterns of Changes in Possible Equilibrium Outcomes as A Function of $\alpha$

This result can be seen very clearly in Figure 2. As $\alpha$ increases, equilibrium outcomes change gradually from Case 1 to Case 5 - i.e., they exhibit less FDI and more FPI. The intuition behind this result is the following: an increase in transparency between owners and managers improves the efficiency of portfolio investments, and thus attracts more investors to this type of investment. This result is consistent with empirical evidence. Indeed, developed economies that have higher corporate-governance transparency tend to have more foreign investments in the form of portfolio investments rather than in the form of direct investments.

Another manifestation of this effect may be that ownership concentration, which clearly generates more control, will be higher in countries, where the laws/institutions provide a lower level of shareholders' rights (which corresponds to a low $\alpha$ ). This is consistent with empirical evidence in La Porta, Lopez-de-Silanes, Shleifer, and Vishny (1998).

Corollary 6: As the level of transparency increases, Case 3, which exhibits full separation between $\lambda_{H}$ and $\lambda_{L}$ investors, is replaced with Case 4, which exhibits only partial separation.

This observation is consistent with the empirical evidence mentioned in the introduction, according to which developing economies tend to exhibit larger differences in volatility between FDI and FPI. Indeed, in our model, Case 3, which exhibits the biggest differences in the rate of early withdrawals between FDI and FPI, is not observed when the level of transparency is very high. 
Rather, it is replaced by Case 4, which exhibits smaller differences in early withdrawals between the two types of investment. The intuition for this result is that as $\alpha$ becomes high, the difference in efficiency between direct investments and portfolio investments becomes small. At the same time, if $\lambda_{H}$ investors invest in portfolio investments, period-1 prices of these investments will be high, attracting some $\lambda_{L}$ investors to switch from FDI to FPI.

\section{Concluding Remarks}

The model we developed in this paper describes an information-based trade off between direct investments and portfolio investments. In the model, direct investors are more informed about the fundamentals of their projects. This information enables them to manage their projects more efficiently. However, it also creates an asymmetric-information problem in case they need to sell their projects prematurely, and reduces the price they can get in that case. As a result, investors, who know they are more likely to get a liquidity shock that forces them to sell early, are more likely to choose portfolio investments, whereas investors, who know they are less likely to get a liquidity shock, are more likely to choose direct investments.

The model generates several results that are consistent with empirical evidence. First, developed economies attract larger shares of FPI than developing economies. This is because the high production costs in developed economies make the projects there less profitable, and thus make it less beneficial to incur the fixed costs associated with FDI. Moreover, the high transparency in developed economies makes FPI there more efficient. Second, since investors with high expected liquidity needs are attracted to FPI, while those with low expected liquidity needs are attracted to FDI, our model can account for the high observed withdrawal rates of FPI relative to FDI, which also contribute to a high volatility of the former relative to the latter. Third, developed economies with high levels of transparency are expected to have smaller differences between the withdrawal ratios of FPI and those of FDI. This is because the high efficiency of FPI in those economies attracts more investors with low expected liquidity needs to FPI, and prevents complete separation in equilibrium between investors with low expected liquidity needs and those with high expected liquidity needs.

In the rest of this section, we highlight six additional implications of our model that seem to us 
as promising directions for future research.

One, the information-based trade off between direct investments and portfolio investments has implications for the expected yields on each type of investment. Thus, in case of a liquidity shock, direct investors get a very low return on their investment. Investors will be willing to bear that risk and make direct investments only if they are compensated in the form of a higher expected yield. In order to address this issue in an appropriate way, our model should be adjusted to include risk averse agents. As for empirical evidence, we are not aware of any empirical study that looked at the differences between the expected yield on direct investments and the expected yield on portfolio investments. We think our framework suggests an interesting testable prediction on this point.

Two, our model can be extended to include debt flows. As is known in the theory of corporate finance, the price of debt is, in most cases, less sensitive to problems of asymmetric information. Thus, in our framework, the return on debt is expected to be less sensitive to liquidity shocks, and thus debt is expected to attract investors with even higher expected liquidity needs.

Three, in Section 5, we developed the implications of transparency for cross-sectional differences in the composition and volatility of foreign equity flows. An interesting extension is to analyze the implications of transparency for time-series differences. Thus, in times of crisis, transparency may be lower, and thus the share of FDI will be larger and the differences in withdrawal rates between FPI and FDI will be larger as well. This seems consistent with casual empirical observations.

Four, as demonstrated in Section 4.3, portfolio investments, in our model, occur sometimes as a result of a coordination failure among investors with high expected liquidity needs. When this happens, the host country can be better-off if investors invest in direct investments. In these scenarios, the government can eliminate the bad equilibrium and improve welfare by encouraging FDI. However, as we also noted in the section, this recommendation should be taken with caution, since in other scenarios encouraging FDI might reduce welfare due to the high set-up costs of this form of investment. We believe that a more thorough analysis should be performed to understand when, in the real world, government intervention is warranted and when it is not. Also, other policy measures may be considered as means to improve welfare. For example, improving the corporate governance and judicial system in the country may enable managers and owners of portfolio investments to write contracts that would entice managers to choose capital as a function of productivity. This would improve not only the efficiency of FPI, but welfare overall. 
Five, our model generates predictions on the reversals of FDI and FPI in equilibrium. In the paper, we used these predictions to shed some light on the differences in volatility between net FDI inflows and net FPI inflows in the real world. We are aware that a full understanding of the differences in volatility requires one to analyze not only the reversals of the two forms of investment, but also the changes in new inflows over time. While this is beyond the scope of the current paper, we think that an extension of our model into a dynamic framework will be useful in conducting this analysis.

Six, our model may be applicable to episodes like the Mexican crisis or the East Asian crisis, where FPI's were reversed much more than FDI's. One problem in this application is that liquidity shocks in our model are idiosyncratic, whereas the liquidity shocks in those episodes were understood to be aggregate shocks affecting the overall market liquidity. Thus, introducing aggregate shocks into the model may be an interesting extension of the current analysis. We believe that such an extension will not change the main results in the paper, especially those on the reversibility of FDI and FPI. The only assumption that is needed for our analysis to go through in the extended framework is that different investors will be affected to different degrees by aggregate liquidity shocks. Then, investors who are very sensitive to aggregate liquidity shocks will choose FPI, whereas those who are less sensitive to aggregate liquidity shocks will choose FDI. This, we believe, will keep the main results of the paper intact.

\section{$7 \quad$ Appendix}

\section{Proof of Proposition 1}

(i) Based on (5) and (6), we know that $\underline{\varepsilon}_{D}\left(\lambda_{D}\right)$ is given implicitly by the following equation:

$$
\frac{\left(1+\underline{\varepsilon}_{D}\right)^{2}}{2 A}=\frac{\left(1-\lambda_{D}\right) \int_{-1}^{\varepsilon_{D}} \frac{(1+\varepsilon)^{2}}{2 A} g(\varepsilon) d \varepsilon+\lambda_{D} \int_{-1}^{1} \frac{1+2 \varepsilon}{2 A} g(\varepsilon) d \varepsilon}{\left(1-\lambda_{D}\right) G\left(\underline{\varepsilon}_{D}\right)+\lambda_{D}}
$$

which can be written as follows:

$$
F\left(\lambda_{D}, \underline{\varepsilon}_{D}\right)=\left(1-\lambda_{D}\right)\left[\int_{-1}^{\underline{\varepsilon}_{D}}\left[(1+\varepsilon)^{2}-\left(1+\underline{\varepsilon}_{D}\right)^{2}\right] g(\varepsilon) d \varepsilon\right]+\lambda_{D}\left[1-\left(1+\underline{\varepsilon}_{D}\right)^{2}\right]=0 .
$$

Analyzing this equation, we can see that as $\lambda_{D}$ approaches $0, \underline{\varepsilon}_{D}\left(\lambda_{D}\right)$ approaches -1 ; and as $\lambda_{D}$ approaches $1, \underline{\varepsilon}_{D}\left(\lambda_{D}\right)$ approaches 0 . Also, for any $\lambda_{D}$ between 0 and $1, \underline{\varepsilon}_{D}\left(\lambda_{D}\right)$ must be below 0 . Now, analyzing the derivatives of $F\left(\lambda_{D}, \underline{\varepsilon}_{D}\right)$, we get: 


$$
\frac{\partial F\left(\lambda_{D}, \underline{\varepsilon}_{D}\right)}{\partial \lambda_{D}}=1-\left(1+\underline{\varepsilon}_{D}\right)^{2}-\int_{-1}^{\underline{\varepsilon}_{D}}\left[(1+\varepsilon)^{2}-\left(1+\underline{\varepsilon}_{D}\right)^{2}\right] g(\varepsilon) d \varepsilon>0,
$$

and

$$
\frac{\partial F\left(\lambda_{D}, \underline{\varepsilon}_{D}\right)}{\partial \underline{\varepsilon}_{D}}=-2\left(1+\underline{\varepsilon}_{D}\right)\left[\left(1-\lambda_{D}\right) G\left(\underline{\varepsilon}_{D}\right)+\lambda_{D}\right]<0 .
$$

Thus, by the Implicit Function Theorem, $\frac{\partial \underline{\varepsilon}_{D}\left(\lambda_{D}\right)}{\partial \lambda_{D}}>0$. As a result, for every $0 \leq \lambda_{D} \leq 1$, there is a unique solution to $\underline{\varepsilon}_{D}$ between -1 and 0 , where $\underline{\varepsilon}_{D}\left(\lambda_{D}\right)$ is monotonically increasing in $\lambda_{D}$.

(ii) This part follows directly from equation (6) that defines $P_{1, D}$ as a function of $\underline{\varepsilon}_{D}$. QED.

\section{Proof of Proposition 2}

From (8), (9), and (10), we know that

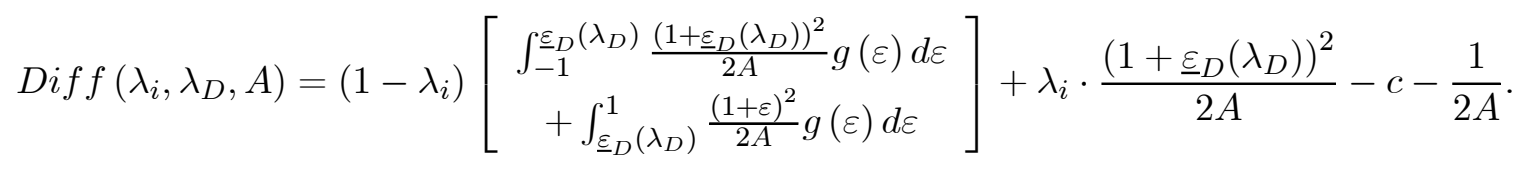

We can rewrite it as:

$$
\operatorname{Diff}\left(\lambda_{i}, \lambda_{D}, A\right)=\frac{1}{2 A} \cdot D\left(\lambda_{i}, \lambda_{D}, A\right)
$$

where

$$
D\left(\lambda_{i}, \lambda_{D}, A\right)=\left(1-\lambda_{i}\right)\left[\begin{array}{c}
\int_{-1}^{\varepsilon_{D}\left(\lambda_{D}\right)}\left(1+\underline{\varepsilon}_{D}\left(\lambda_{D}\right)\right)^{2} g(\varepsilon) d \varepsilon \\
+\int_{\underline{\varepsilon}_{D}\left(\lambda_{D}\right)}^{1}(1+\varepsilon)^{2} g(\varepsilon) d \varepsilon
\end{array}\right]+\lambda_{i} \cdot\left(1+\underline{\varepsilon}_{D}\left(\lambda_{D}\right)\right)^{2}-2 A c-1 .
$$

Then, the decision of investors between FDI and FPI depends on the sign of $D\left(\lambda_{i}, \lambda_{D}, A\right)$. An increase (decrease) in $D\left(\lambda_{i}, \lambda_{D}, A\right)$ makes it more likely that the investor will choose FDI (FPI). We now show that the signs of the derivatives of $D\left(\lambda_{i}, \lambda_{D}, A\right)$ with respect to the different parameters support the four parts of the proposition.

(i)

$$
\frac{\partial D\left(\lambda_{i}, \lambda_{D}, A\right)}{\partial c}=-2 A<0
$$

(ii)

$$
\frac{\partial D\left(\lambda_{i}, \lambda_{D}, A\right)}{\partial A}=-2 c<0
$$

$$
\begin{aligned}
\frac{\partial D\left(\lambda_{i}, \lambda_{D}, A\right)}{\partial \lambda_{i}} & =\left(1+\underline{\varepsilon}_{D}\left(\lambda_{D}\right)\right)^{2}-\int_{-1}^{\underline{\varepsilon}_{D}\left(\lambda_{D}\right)}\left(1+\underline{\varepsilon}_{D}\left(\lambda_{D}\right)\right)^{2} g(\varepsilon) d \varepsilon-\int_{\underline{\varepsilon}_{D}\left(\lambda_{D}\right)}^{1}(1+\varepsilon)^{2} g(\varepsilon) d \varepsilon \\
& =\int_{\underline{\varepsilon}_{D}\left(\lambda_{D}\right)}^{1}\left[\left(1+\underline{\varepsilon}_{D}\left(\lambda_{D}\right)\right)^{2}-(1+\varepsilon)^{2}\right] g(\varepsilon) d \varepsilon<0 .
\end{aligned}
$$


(iv)

$$
\frac{\partial D\left(\lambda_{i}, \lambda_{D}, A\right)}{\partial \lambda_{D}}=2 \frac{\partial \underline{\varepsilon}_{D}\left(\lambda_{D}\right)}{\partial \lambda_{D}}\left(1+\underline{\varepsilon}_{D}\left(\lambda_{D}\right)\right)\left[\left(1-\lambda_{i}\right) G\left(\underline{\varepsilon}_{D}\left(\lambda_{D}\right)\right)+\lambda_{i}\right]>0,
$$

where we used the result in Proposition 1 to tell that $\frac{\partial \underline{\varepsilon}_{D}\left(\lambda_{D}\right)}{\partial \lambda_{D}}>0$. QED.

\section{Proof of Proposition 3:}

We start by defining the conditions for each case to be an equilibrium. We base these conditions on: The equilibrium choice of agents between FDI and FPI, as defined in Section 3; the equilibrium value of $\lambda_{D}$, as defined in Section 4 (including the off-equilibrium assumption); and the properties of the function $D\left(\lambda_{i}, \lambda_{D}, A\right)$, as shown in the proof of Proposition 2. Then, the conditions are as follows: Case 1 is an equilibrium iff $D\left(\lambda_{H}, \frac{1}{2}, A\right) \geq 0$. Case 2 is an equilibrium iff $D\left(\lambda_{H}, \lambda_{L}, A\right)$ $\leq 0$ and $D\left(\lambda_{H}, \frac{1}{2}, A\right) \geq 0$. Case 3 is an equilibrium iff $D\left(\lambda_{H}, \lambda_{L}, A\right) \leq 0$ and $D\left(\lambda_{L}, \lambda_{L}, A\right) \geq 0$. Case 4 is an equilibrium iff $D\left(\lambda_{L}, \lambda_{L}, A\right)=0$. Case 5 is an equilibrium iff $D\left(\lambda_{L}, \lambda_{L}, A\right) \leq 0$.

Now, we define the thresholds $\lambda_{H}^{*}(A), \lambda_{H}^{* *}(A)$, and $\lambda_{H}^{* * *}(A)$ that are included in the proposition. Threshold $\lambda_{H}^{*}(A)$ is defined by the equation: $D\left(\lambda_{H}^{*}(A), \lambda_{L}^{*}(A), A\right)=0$ (here, $\left.\lambda_{L}^{*}(A) \equiv 1-\lambda_{H}^{*}(A)\right)$. Threshold $\lambda_{H}^{* *}(A)$ is defined by: $D\left(\lambda_{H}^{* *}(A), \frac{1}{2}, A\right)=0$. Finally, threshold $\lambda_{H}^{* * *}(A)$ is defined by: $D\left(\lambda_{L}^{* * *}(A), \lambda_{L}^{* * *}(A), A\right)=0$ (here, $\left.\lambda_{L}^{* * *}(A) \equiv 1-\lambda_{H}^{* * *}(A)\right)$.

Now, we characterize these thresholds as functions of $A$. The illustration provided in Figure 1 can help in understanding this part of the proof. First, note that $\lambda_{H}^{*}\left(A^{*}\right)=\lambda_{H}^{* *}\left(A^{*}\right)=\lambda_{H}^{* * *}\left(A^{*}\right)=\frac{1}{2}$. (Recall that $A^{*}$ is defined in (12).) Then, by the properties of $D\left(\lambda_{i}, \lambda_{D}, A\right)$, which were shown in the proof of Proposition 2, we know that both $\lambda_{H}^{*}(A)$ and $\lambda_{H}^{* *}(A)$ are decreasing in $A$, and that $\lambda_{H}^{* *}(A)>\lambda_{H}^{*}(A)$. Also, by examining the function $D\left(\lambda_{i}, \lambda_{D}, A\right)$, we can tell that $\lambda_{H}^{* *}(0)<1$. Finally, since $D(\lambda, \lambda, A)$ is decreasing in $\lambda$ (this is shown at the end of this proof) and in $A$ (as was shown in the proof of Proposition 2), $\lambda_{H}^{* * *}(A)$ is increasing in $A$.

Using the equilibrium conditions, we can now specify when each equilibrium will occur relative to the thresholds defined above. This specification relies on the properties of the function $D\left(\lambda_{i}, \lambda_{D}, A\right)$, which were shown in the proof of Proposition 2, and on the property that $D(\lambda, \lambda, A)$ is decreasing in $\lambda$, which will be shown below. Case 1 is an equilibrium iff $\lambda_{H} \leq \lambda_{H}^{* *}(A)$. Case 2 is an equilibrium iff $\lambda_{H}^{*}(A) \leq \lambda_{H} \leq \lambda_{H}^{* *}(A)$. Case 3 is an equilibrium iff $\lambda_{H} \geq \lambda_{H}^{*}(A)$ and $\lambda_{H} \geq \lambda_{H}^{* * *}(A)$. Case 4 is an equilibrium iff $\lambda_{H}=\lambda_{H}^{* * *}(A)$. Case 5 is an equilibrium iff $\lambda_{H} \leq \lambda_{H}^{* * *}(A)$. This leads to the characterization of equilibrium outcomes stated in the proposition.

To complete the proof, we need to show that $D(\lambda, \lambda, A)$ is decreasing in $\lambda$. We know that: 


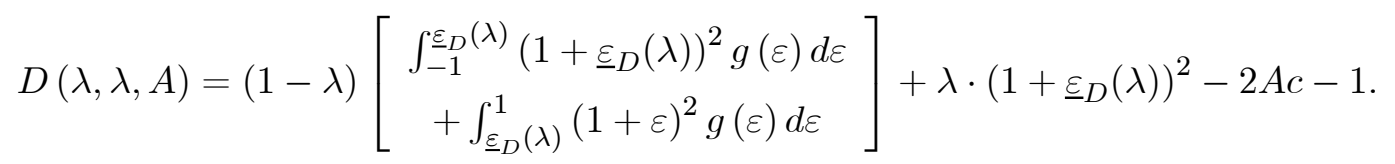

Thus,

$$
\begin{aligned}
\frac{\partial D(\lambda, \lambda, A)}{\partial \lambda}= & \int_{\underline{\varepsilon}_{D}(\lambda)}^{1}\left[\left(1+\underline{\varepsilon}_{D}(\lambda)\right)^{2}-(1+\varepsilon)^{2}\right] g(\varepsilon) d \varepsilon \\
& +2 \frac{\partial \underline{\varepsilon}_{D}(\lambda)}{\partial \lambda}\left(1+\underline{\varepsilon}_{D}(\lambda)\right)\left[(1-\lambda) G\left(\underline{\varepsilon}_{D}(\lambda)\right)+\lambda\right] .
\end{aligned}
$$

Plugging in the expression for $\frac{\partial \underline{\varepsilon}_{D}(\lambda)}{\partial \lambda}$, as is implied by (5) and (6), we get:

$$
\begin{aligned}
\frac{\partial D(\lambda, \lambda, A)}{\partial \lambda}= & \int_{\underline{\varepsilon}_{D}(\lambda)}^{1}\left[\left(1+\underline{\varepsilon}_{D}(\lambda)\right)^{2}-(1+\varepsilon)^{2}\right] g(\varepsilon) d \varepsilon \\
& +\left(1-\left(1+\underline{\varepsilon}_{D}(\lambda)\right)^{2}\right)+\int_{-1}^{\underline{\varepsilon}_{D}(\lambda)}\left[\left(1+\underline{\varepsilon}_{D}(\lambda)\right)^{2}-(1+\varepsilon)^{2}\right] g(\varepsilon) d \varepsilon \\
= & 1-\int_{-1}^{1}(1+\varepsilon)^{2} g(\varepsilon) d \varepsilon<0
\end{aligned}
$$

\section{QED.}

\section{Characterization of $\underline{\varepsilon}_{P}\left(\alpha, \lambda_{P}\right)$}

Equation (14) can be written as:

$$
F_{P}\left(\lambda_{P}, \alpha, \underline{\varepsilon}_{P}\right)=\left(1-\lambda_{P}\right) \alpha \int_{-1}^{\underline{\varepsilon}_{P}}\left[(1+\varepsilon)^{2}-\left(1+\underline{\varepsilon}_{P}\right)^{2}\right] g(\varepsilon) d \varepsilon+\lambda_{P}\left[1-\left(1+\underline{\varepsilon}_{P}\right)^{2}\right]=0 .
$$

The partial derivatives of $F_{P}\left(\lambda_{P}, \alpha, \underline{\varepsilon}_{P}\right)$ with respect to $\lambda_{P}, \alpha$ and $\underline{\varepsilon}_{P}$ are:

$$
\begin{gathered}
\frac{\partial F_{P}\left(\lambda_{P}, \alpha, \underline{\varepsilon}_{P}\right)}{\partial \lambda_{P}}=\left[1-\left(1+\underline{\varepsilon}_{P}\right)^{2}\right]-\alpha \int_{-1}^{\underline{\varepsilon}_{P}}\left[(1+\varepsilon)^{2}-\left(1+\underline{\varepsilon}_{P}\right)^{2}\right] g(\varepsilon) d \varepsilon>0, \\
\frac{\partial F_{P}\left(\lambda_{P}, \alpha, \underline{\varepsilon}_{P}\right)}{\partial \alpha}=\left(1-\lambda_{P}\right) \int_{-1}^{\underline{\varepsilon}_{P}}\left[(1+\varepsilon)^{2}-\left(1+\underline{\varepsilon}_{P}\right)^{2}\right] g(\varepsilon) d \varepsilon<0,
\end{gathered}
$$

and

$$
\frac{\partial F_{P}\left(\lambda_{P}, \alpha, \underline{\varepsilon}_{P}\right)}{\partial \underline{\varepsilon}_{P}}=-2\left(1+\underline{\varepsilon}_{P}\right)\left[\left(1-\lambda_{P}\right) \alpha G\left(\underline{\varepsilon}_{P}\right)+\lambda_{P}\right]<0 .
$$

Then, using the Implicit Function Theorem, we get that $\frac{\partial \underline{\varepsilon}_{P}\left(\alpha, \lambda_{P}\right)}{\partial \alpha}<0$, and $\frac{\partial \underline{\varepsilon}_{P}\left(\alpha, \lambda_{P}\right)}{\partial \lambda_{P}}>0$. Moreover, when $\lambda_{P}$ approaches $1, \underline{\varepsilon}_{P}$ approaches 0 ; when $\lambda_{P}$ approaches $0, \underline{\varepsilon}_{P}$ approaches -1 ; 
when $\alpha$ approaches $1, \underline{\varepsilon}_{P}$ approaches $\underline{\varepsilon}_{D}(\leq 0)$; and when $\alpha$ approaches $0, \underline{\varepsilon}_{P}$ approaches 0 . Thus, for every $\lambda_{P}$ and $\alpha$ between 0 and 1, there is a unique solution for $\underline{\varepsilon}_{P}$ between -1 and 0 . QED.

\section{Proof of Proposition 4}

We define the function $\operatorname{Dif} f_{\alpha}\left(\lambda_{i}, \lambda_{D}, \lambda_{P}\right)$ to capture the difference between the expected value of FDI and the expected value of FPI. It is given as follows:

$\operatorname{Diff} f_{\alpha}\left(\lambda_{i}, \lambda_{D}, \lambda_{P}\right)=\frac{1}{2 A}\left[+\left(1-\lambda_{i}\right)\left[\begin{array}{c}\lambda_{i}\left[\left(1+\underline{\varepsilon}_{D}\left(\lambda_{D}\right)\right)^{2}-\left(1+\underline{\varepsilon}_{P}\left(\alpha, \lambda_{p}\right)\right)^{2}\right] \\ \int_{-1}^{\varepsilon_{D}\left(\lambda_{D}\right)}\left(1+\underline{\varepsilon}_{D}\left(\lambda_{D}\right)\right)^{2} g(\varepsilon) d \varepsilon+\int_{\underline{\varepsilon}_{D}\left(\lambda_{D}\right)}^{1}(1+\varepsilon)^{2} g(\varepsilon) d \varepsilon \\ -(1-\alpha)-\alpha \int_{-1}^{\underline{\varepsilon}_{P}\left(\alpha, \lambda_{p}\right)}\left(1+\underline{\varepsilon}_{P}\left(\alpha, \lambda_{p}\right)\right)^{2} g(\varepsilon) d \varepsilon \\ -\alpha \int_{\underline{\varepsilon}_{P}\left(\alpha, \lambda_{p}\right)}^{1}(1+\varepsilon)^{2} g(\varepsilon) d \varepsilon\end{array}\right]\right.$

We start by studying the derivatives of $\operatorname{Dif} f_{\alpha}\left(\lambda_{i}, \lambda_{D}, \lambda_{P}\right)$ with respect to the parameters $\lambda_{D}$, $\lambda_{P}, \lambda_{i}$, and $\alpha$ :

$$
\begin{aligned}
& \frac{\partial D i f f_{\alpha}\left(\lambda_{i}, \lambda_{D}, \lambda_{P}\right)}{\partial \lambda_{D}}=2 \frac{1}{2 A} \frac{\partial \underline{\varepsilon}_{D}\left(\lambda_{D}\right)}{\partial \lambda_{D}}\left(1+\underline{\varepsilon}_{D}\left(\lambda_{D}\right)\right)\left[\left(1-\lambda_{i}\right) G\left(\underline{\varepsilon}_{D}\left(\lambda_{D}\right)\right)+\lambda_{i}\right]>0 . \\
& \frac{\partial D i f f_{\alpha}\left(\lambda_{i}, \lambda_{D}, \lambda_{P}\right)}{\partial \lambda_{P}}=-2 \frac{1}{2 A} \frac{\partial \underline{\varepsilon}_{P}\left(\alpha, \lambda_{P}\right)}{\partial \lambda_{P}}\left(1+\underline{\varepsilon}_{P}\left(\alpha, \lambda_{P}\right)\right)\left[\alpha\left(1-\lambda_{i}\right) G\left(\underline{\varepsilon}_{P}\left(\alpha, \lambda_{P}\right)\right)+\lambda_{i}\right]<0 . \\
& \frac{\partial \operatorname{Diff} f_{\alpha}\left(\lambda_{i}, \lambda_{D}, \lambda_{P}\right)}{\partial \lambda_{i}}=\frac{1}{2 A} \int_{\underline{\varepsilon}_{D}\left(\lambda_{D}\right)}^{1}\left[\left(1+\underline{\varepsilon}_{D}\left(\lambda_{D}\right)\right)^{2}-(1+\varepsilon)^{2}\right] g(\varepsilon) d \varepsilon \\
& +\frac{1}{2 A}(1-\alpha)\left[1-\left(1+\underline{\varepsilon}_{P}\left(\alpha, \lambda_{p}\right)\right)^{2}\right] \\
& +\frac{1}{2 A} \alpha \int_{\underline{\varepsilon}_{P}\left(\alpha, \lambda_{p}\right)}^{1}\left[(1+\varepsilon)^{2}-\left(1+\underline{\varepsilon}_{P}\left(\alpha, \lambda_{p}\right)\right)^{2}\right] g(\varepsilon) d \varepsilon \text {. }
\end{aligned}
$$

This expression is negative. To see why, note that the only way to make it non-negative is to have $\underline{\varepsilon}_{P}\left(\alpha, \lambda_{p}\right)<\underline{\varepsilon}_{D}\left(\lambda_{D}\right)$. This implies that $\lambda_{p}<\lambda_{D}$, and also that Diff $f_{\alpha}\left(\lambda_{i}, \lambda_{D}, \lambda_{P}\right)$ is positive for both $\lambda_{H}$ and $\lambda_{L}$ investors. However, these two implications contradict each other, as the second one implies that all investors choose FDI in equilibrium, which means that $\lambda_{p}$ cannot be smaller than $\lambda_{D}$.

$$
\begin{aligned}
& \frac{\partial \operatorname{Diff} f_{\alpha}\left(\lambda_{i}, \lambda_{D}, \lambda_{P}\right)}{\partial \alpha}=\frac{1}{2 A}\left(1-\lambda_{i}\right)\left[\begin{array}{c}
1-\int_{-1}^{\varepsilon_{P}\left(\alpha, \lambda_{p}\right)}\left(1+\underline{\varepsilon}_{P}\left(\alpha, \lambda_{p}\right)\right)^{2} g(\varepsilon) d \varepsilon \\
-\int_{\underline{\varepsilon}_{P}\left(\alpha, \lambda_{p}\right)}^{1}(1+\varepsilon)^{2} g(\varepsilon) d \varepsilon
\end{array}\right] \\
& -\frac{1}{2 A} 2 \frac{\partial \underline{\varepsilon}_{P}\left(\alpha, \lambda_{P}\right)}{\partial \alpha}\left(1+\underline{\varepsilon}_{P}\left(\alpha, \lambda_{P}\right)\right)\left[\left(1-\lambda_{i}\right) \alpha G\left(\underline{\varepsilon}_{P}\left(\alpha, \lambda_{P}\right)\right)+\lambda_{i}\right] \text {. }
\end{aligned}
$$


This can be rewritten as:

$$
\begin{aligned}
& \frac{1}{2 A}\left(1-\lambda_{i}\right)\left[\begin{array}{c}
1-\int_{-1}^{\underline{\varepsilon}_{P}\left(\alpha, \lambda_{p}\right)}\left(1+\underline{\varepsilon}_{P}\left(\alpha, \lambda_{p}\right)\right)^{2} g(\varepsilon) d \varepsilon \\
-\int_{\underline{\varepsilon}_{P}\left(\alpha, \lambda_{p}\right)}^{1}(1+\varepsilon)^{2} g(\varepsilon) d \varepsilon
\end{array}\right] \\
& +\frac{1}{2 A} \frac{\left(1-\lambda_{i}\right) \alpha G\left(\underline{\varepsilon}_{P}\left(\alpha, \lambda_{P}\right)\right)+\lambda_{i}}{\left(1-\lambda_{P}\right) \alpha G\left(\underline{\varepsilon}_{P}\left(\alpha, \lambda_{P}\right)\right)+\lambda_{P}}\left(1-\lambda_{P}\right) \int_{-1}^{\underline{\varepsilon}_{P}\left(\alpha, \lambda_{P}\right)}\left[\left(1+\underline{\varepsilon}_{P}\left(\alpha, \lambda_{P}\right)\right)^{2}-(1+\varepsilon)^{2}\right] g(\varepsilon) d \varepsilon .
\end{aligned}
$$

We can see that this is negative whenever $\lambda_{P} \geq \lambda_{i}$.

Now, we turn to characterize the equilibrium outcomes. Since $\frac{\partial \operatorname{Diff} f_{\alpha}\left(\lambda_{i}, \lambda_{D}, \lambda_{P}\right)}{\partial \lambda_{i}}<0$, the only possible cases in equilibrium are cases 1-5. Then, following the logic in the proof of Proposition 3 , we define the conditions for each case to be an equilibrium as follows. Case 1 is an equilibrium iff $\operatorname{Diff}_{\alpha}\left(\lambda_{H}, \frac{1}{2}, \lambda_{H}\right) \geq 0$. Case 2 is an equilibrium iff Diff $f_{\alpha}\left(\lambda_{H}, \lambda_{L}, \lambda_{H}\right) \leq 0$ and $\operatorname{Diff}_{\alpha}\left(\lambda_{H}, \frac{1}{2}, \lambda_{H}\right) \geq 0$. Case 3 is an equilibrium iff Diff $f_{\alpha}\left(\lambda_{H}, \lambda_{L}, \lambda_{H}\right) \leq 0$ and Dif $f_{\alpha}\left(\lambda_{L}, \lambda_{L}, \lambda_{H}\right)$ $\geq 0$. Case 4 is an equilibrium iff Diff $f_{\alpha}\left(\lambda_{L}, \lambda_{L}, \lambda_{H}\right) \leq 0$ and Dif $f_{\alpha}\left(\lambda_{L}, \lambda_{L}, \frac{1}{2}\right) \geq 0$. Case 5 is an equilibrium iff $\operatorname{Diff} f_{\alpha}\left(\lambda_{L}, \lambda_{L}, \frac{1}{2}\right) \leq 0$.

We can see that the analysis of equilibrium outcomes boils down to determining whether each one of four threshold values of the function $\operatorname{Dif} f_{\alpha}(\cdot, \cdot, \cdot)$ is positive or negative. These threshold values are: $\operatorname{Dif} f_{\alpha}\left(\lambda_{H}, \frac{1}{2}, \lambda_{H}\right)$, Diff $f_{\alpha}\left(\lambda_{H}, \lambda_{L}, \lambda_{H}\right)$, Diff $f_{\alpha}\left(\lambda_{L}, \lambda_{L}, \lambda_{H}\right)$, and Diff $f_{\alpha}\left(\lambda_{L}, \lambda_{L}, \frac{1}{2}\right)$. Since all four threshold values satisfy $\lambda_{P} \geq \lambda_{i}$, they are all decreasing in $\alpha$. As a result, as $\alpha$ increases, we gradually move from a situation where all thresholds are positive, via situations where some are positive and some are negative, to a situation where they are all negative. The exact order of the four threshold values will determine the exact pattern, and this will dictate the effect of $\alpha$ on possible equilibrium outcomes.

To complete the proof, we thus need to study the order of the four threshold values. Since $\frac{\partial \operatorname{Diff} f_{\alpha}\left(\lambda_{i}, \lambda_{D}, \lambda_{P}\right)}{\partial \lambda_{i}}<0, \frac{\partial D i f f_{\alpha}\left(\lambda_{i}, \lambda_{D}, \lambda_{P}\right)}{\partial \lambda_{D}}>0$, and $\frac{\partial D i f f_{\alpha}\left(\lambda_{i}, \lambda_{D}, \lambda_{P}\right)}{\partial \lambda_{P}}<0$, we know that the threshold $\operatorname{Diff} f_{\alpha}\left(\lambda_{H}, \lambda_{L}, \lambda_{H}\right)$ is the lowest of the four thresholds. We also know that $\operatorname{Diff} f_{\alpha}\left(\lambda_{L}, \lambda_{L}, \lambda_{H}\right)<$ Dif $f_{\alpha}\left(\lambda_{L}, \lambda_{L}, \frac{1}{2}\right)$. Thus, there are only three possible orders for the four threshold signals: The first one is: $\operatorname{Diff}_{\alpha}\left(\lambda_{H}, \lambda_{L}, \lambda_{H}\right)<\operatorname{Diff}_{\alpha}\left(\lambda_{H}, \frac{1}{2}, \lambda_{H}\right)<\operatorname{Diff}_{\alpha}\left(\lambda_{L}, \lambda_{L}, \lambda_{H}\right)<\operatorname{Diff} f_{\alpha}\left(\lambda_{L}, \lambda_{L}, \frac{1}{2}\right)$. The second one is: Diff $f_{\alpha}\left(\lambda_{H}, \lambda_{L}, \lambda_{H}\right)<\operatorname{Diff} f_{\alpha}\left(\lambda_{L}, \lambda_{L}, \lambda_{H}\right)<\operatorname{Diff} f_{\alpha}\left(\lambda_{H}, \frac{1}{2}, \lambda_{H}\right)<\operatorname{Diff} f_{\alpha}\left(\lambda_{L}, \lambda_{L}, \frac{1}{2}\right)$. The third one is: Diff $f_{\alpha}\left(\lambda_{H}, \lambda_{L}, \lambda_{H}\right)<\operatorname{Diff} f_{\alpha}\left(\lambda_{L}, \lambda_{L}, \lambda_{H}\right)<\operatorname{Diff} f_{\alpha}\left(\lambda_{L}, \lambda_{L}, \frac{1}{2}\right)<\operatorname{Diff} f_{\alpha}\left(\lambda_{H}, \frac{1}{2}, \lambda_{H}\right)$. Analyzing the conditions for the different equilibrium outcomes, we can see that these three orders dictate the three patterns, mentioned in the proposition, along which $\alpha$ affects the possible 
equilibrium outcomes. QED.

\section{References}

[1] Admati, A. R. and P. Pfleiderer, 1988, "A Theory of Intraday Patterns: Volume and Price Variability," Review of Financial Studies, 1, 3-40.

[2] Admati, A. R. and P. Pfleiderer, 1991, "Sunshine Trading and Financial Market Equilibrium," Review of Financial Studies, 4, 443-481.

[3] Akerlof, G. A., 1970, "The Market for Lemons: Quality Uncertainty and the Market Mechanism," Quarterly Journal of Economics, 84, 488-500.

[4] Albuquerque, R., 2003, "The Composition of International Capital Flows: Risk Sharing Through Foreign Direct Investment," Journal of International Economics, 61, 353-383.

[5] Bolton, P. and E. L. von Thadden, 1998, "Blocks, Liquidity, and Corporate Control," Journal of Finance, 53, 1-25.

[6] Chan, L. and J. Lakonishok, 1995, "The Behavior of Stock Prices around Institutional Trades," Journal of Finance, 50, 1147-1174.

[7] Chari, A., P. P. Ouimet and L. Tesar, 2005, "Acquiring Control in Emerging Markets: Evidence from the Stock Market," Working Paper, University of Michigan.

[8] Chuhan, P., G. Perez-Quiros and H. Popper, 1996, "Do Short-term Investment and Direct Investment Differ?," World Bank Policy Research Working Paper, 1669.

[9] Diamond, D. W. and P. H. Dybvig, 1983, "Bank Runs, Deposit Insurance, and Liquidity," Journal of Political Economy, 91, 401-419.

[10] Downes, D. H. and R. Heinkel, 1982, "Signaling and the Valuation of Unseasoned New Issues," Journal of Finance, 37, 1-10.

[11] Foster, F. D. and S. Viswanathan, 1990, "A Theory of the Interday Variations in Volume, Variance, and Trading Costs in Securities Markets," Review of Financial Studies, 3, 593-624. 
[12] Frankel, J. A. and A. K. Rose, 1996, "Currency Crashes in Emerging Markets: An Empirical Treatment," Journal of International Economics, 41, 351-366.

[13] Froot, K. A. and J. C. Stein, 1991, "Exchange Rates and Foreign Direct Investment: An Imperfect Capital Markets Approach," Quarterly Journal of Economics, 106, 1191-1217.

[14] Gordon, R. H. and A. Lans Bovenberg, 1996, "Why Is Capital So Immobile Internationally? Possible Explanations and Implications for Capital Income Taxation," American Economic Review, 86, 1057-1075.

[15] Hart, O., 2001, "Financial Contracting," Journal of Economic Literature, 34, 1079-1100.

[16] Hennart, J., D. Kim and M. Zeng, 1998, "The Impact of Joint Venture Status on the Longevity of Japanese Stakes in U.S. Manufacturing Affiliates," Organization Science, 9, 382-395.

[17] Hertzel, M. and R. Smith, 1993, "Market Discounts and Shareholder Gains for Placing Equity Privately," Journal of Finance, 48, 459-485.

[18] Holthausen, R. W., R. W. Leftwich and D. Mayers, 1990, "Large-Block Transactions, the Speed of Response, and Temporary and Permanent Stock-Price Effects," Journal of Financial Economics, 26, 71-95.

[19] Jensen, M., 1986, "The Agency Costs of Free Cash Flow: Corporate Finance and Takeovers," American Economic Review, 76, 323-330.

[20] Kahn, C. and A. Winton, 1998, "Ownership Structure, Speculation, and Shareholder Intervention," Journal of Finance, 53, 99-129.

[21] Klein, M. W. and E. S. Rosengren, 1994, "The Real Exchange Rate and Foreign Direct Investment in the United States," Journal of International Economics, 36, 373-389.

[22] Klein, M. W., J. Peek and E. S. Rosengren, 2002, "Troubled Banks, Impaired Foreign Direct Investment: The Role of Relative Access to Credit," American Economic Review, 92, 664-682.

[23] Korajczyk, R. A., D. J. Lucas and R. L. McDonald, 1991, "The Effect of Information Releases on the Pricing and Timing of Equity Issues," Review of Financial Studies, 4, 685-708. 
[24] La Porta, R., F. Lopez-de-Silanes, A. Shleifer and R. W. Vishny, 1998, "Law and Finance," Journal of Political Economy, 106, 1113-1155.

[25] Lipsey, R. E., 1999, "The Role of Foreign Direct Investment in International Capital Flows," NBER Working Paper, 7094.

[26] Lipsey, R. E., 2001, "Foreign Direct Investors in Three Financial Crises," NBER Working Paper, 8084.

[27] Masulis, R. W. and A. N. Korwar, 1986, "Seasoned Equity Offerings: An Empirical Investigation," Journal of Financial Economics, 15, 91-118.

[28] Maug, E., 1998, "Large Shareholders as Monitors: Is There a trade off between Liquidity and Control?," Journal of Finance, 53, 65-98.

[29] Mikkelson, W. H. and M. Partch, 1985, "Stock Price Effects and Costs of Secondary Distributions," Journal of Financial Economics, 14, 165-194.

[30] Perez-Gonzalez, F., 2005, "The Impact of Acquiring Control on Productivity,” Working Paper, Columbia University.

[31] Razin, A. and E. Sadka, 2003, "Gains from FDI Inflows with Incomplete Information," Economics Letters, 7, 71-77.

[32] Razin, A., E. Sadka and C-W Yuen, 1998, "A Pecking Order of Capital Inflows and International Tax Principles," Journal of International Economics, 44, 45-68.

[33] Sarno, L. and M. P. Taylor, 1999, "Hot Money, Accounting Labels and the Permanence of Capital Flows to Developing Countries: An Empirical Investigation," Journal of Developments Economics, 59, 337-364.

[34] Shleifer, A. and R. W. Vishny, 1986, "Large Shareholders and Corporate Control," Journal of Political Economy, 94, 461-488.

[35] Wruck, K., 1989, "Equity Ownership Concentration and Firm Value: Evidence from Private Equity Financings," Journal of Financial Economics, 23, 3-28. 